\title{
Mechanisms matter for evaluating the economic impacts of marine reserves ${ }^{i}$
}

\author{
Matthew N. Reimer ${ }^{\mathrm{a}, *}$, Alan C. Haynie ${ }^{\mathrm{b}}$ \\ a Institute of Social and Economic Research, Department of Economics and Public Policy, University of Alaska Anchorage, 3211 Providence \\ Drive, Anchorage, AK 99508, USA \\ ${ }^{\mathrm{b}}$ Resource Ecology and Fisheries Management Division, Alaska Fisheries Science Center, National Marine Fisheries Service, NOAA, 7600 \\ Sand Point Way NE, Bldg. 4, Seattle, WA 98115, USA
}

\section{A R T I C L E I N F O}

\section{Article history:}

Received 28 June 2017

Received in revised form

14 October 2017

Accepted 23 January 2018

Available online 17 February 2018

\section{Keywords:}

Program evaluation

Spatial closures

Marine reserves

Synthetic control

Propensity score

Mechanisms

Mediation analysis

Structural equation modeling

Fisheries

JEL classification:

C31

Q20

Q22

Q28

\begin{abstract}
A B S T R A C T
Large areas of marine and coastal environments have been protected to satisfy diverse policy goals, but there has been limited work understanding the economic impacts of such closures. While methods for establishing causal impacts are prevalent, less attention has been paid to explaining the mechanisms through which the causal relationship came to be. Understanding mechanisms is crucial for designing policies that foster the mechanisms that achieve the intended objectives of marine reserves and mitigate the mechanisms that do not. We estimate the treatment effect of a large marine reserve on the net earnings of a commercial fishery using difference-in-differences and synthetic-control designs, and decompose the treatment effect into its constituent mechanisms through structural equation modeling. We find minimal evidence that closing the marine reserve to fishing had a significant economic cost for the industry; however, several counteracting mechanisms are critical for explaining the effect and for generalizing to other settings.
\end{abstract}

(c) 2018 Elsevier Inc. All rights reserved.

\section{Introduction}

Program evaluation is a critical element of evidence-based policy making for natural resource and environmental management (Ferraro, 2009). When conducted properly, program evaluations assess the degree to which changes in an

\footnotetext{
${ }_{25}^{2}$ MR and AH conceived of the research methods, performed the analysis, and wrote the paper. The authors wish to thank the Spatial Economics Toolbox for Fisheries (FishSET) project and NMFS Science \& Technology for funding for MR. Thanks to Dave Colpo and Carlo Barstow from Pacific States for assistance with contracting and to Jean Lee of AKFIN for assistance with the production data. We wish to thank Ben Muse for helping to conceive of an expost analysis of the policy and for input on the research design and the manuscript. Thanks to Chloe Tanaka for research assistance and to Josh Keaton and Steve Lewis of the NMFS Region for input on this and related previous analyses. Finally, thanks to Mouhcine Guettabi, Andrew Bibler, Joshua Abbott, Steve Kasperski, and two anonymous reviewers for helpful comments.

* Corresponding author.

E-mail addresses: mreimer2@alaska.edu (M.N. Reimer), alan.haynie@noaa.gov (A.C. Haynie).
} 
outcome variable can be attributed solely to a particular policy, and are therefore essential for eliminating any plausible explanations of the outcomes that are unrelated to the policy. Most of the program evaluation literature is devoted to establishing whether a program causally affected an outcome variable; in contrast, relatively few evaluations explain how or why such a causal relationship came to be (Imai et al., 2011). Understanding the mechanisms through which a program influences an outcome variable is important for both testing economic theory and for generalizing results beyond the setting at hand (Heckman and Smith, 1995). Moreover, understanding mechanisms can aid policy makers in designing policies that foster the mechanisms that achieve the intended policy objectives and mitigate the mechanisms that do not (Ferraro and Hanauer, 2014).

We estimate the causal short-run economic impacts and the underlying mechanisms associated with a large marine reserve for the protection of the endangered western stock of Steller sea lions (SSL) in U. S. waters off the coast of Alaska. Marine reserves, or spatial closures more generally, prohibit some or all fishing in a defined geographic area for a specific period of time, and are among the primary tools of marine resource managers in the world. Indeed, the United Nations, national and state governments, and other management agencies having formal goals of placing 10-30 percent of the oceans in marine reserves (Wabnitz et al., 2010). The potential long-term benefits of marine reserves, such as the protection of vulnerable species (Hooker and Gerber, 2004) and/or the spillover effects of rebuilt stocks (e.g., Abesamis and Russ, 2005), are well known and have been discussed thoroughly (e.g., Gaines et al., 2010). However, empirical estimates of the short-run costs incurred by the commercial fishing industry are relatively scarce. Marine reserves can change the opportunities available to fishers-for instance, by forcing them out of productive fishing areas and/or constraining their ability to balance multispecies catch compositions in accordance with annual speciesspecific harvest quotas (Abbott et al., 2015). A marine reserve may therefore increase short-run costs or reduce revenues, possibly outweighing the benefits of the reserve. Thus, evaluating the short-run costs incurred by the fishing industry relative to any benefits of marine reserves is a critical element for evidence-based policy making for ecosystem-based fisheries management (Smith et al., 2010; Sanchirico et al., 2013).

Previous evaluations of the short-run cost of marine reserves are predominantly ex ante analyses, which rely on predictive models of how fishers adjust their behavior in response to a potential spatial closure (e.g., Holland and Brazee, 1996; Hannesson, 1998; Sanchirico and Wilen, 2001; Smith and Wilen, 2003; Berman, 2006; Haynie and Layton, 2010). Unfortunately, evaluating the impact of a marine reserve ex post is complicated by the fact that reserves are not implemented in a manner that facilitates the measurement of their causal impact (Smith et al., 2006). For instance, the implementation of a marine reserve rarely generates clear "treated" and "control" groups in which one group of fishermen is not permitted to fish in an area while others are, thereby impeding estimation of the counterfactual outcomes that would have occurred without the closure. In addition, marine reserves typically do not occur in isolation; other factors that influence fishingrelated outcomes inevitably change simultaneously, such as total allowable catches (TACs), prices, abundances, etc. Thus, simply using outcomes from before and after implementation of a marine reserve may not isolate the effect of the closure from other simultaneous changes.

Our evaluation of the short-run economic impacts of a spatial closure for SSL protection addresses several important issues that have impeded ex post evaluations of marine reserves in the past, and makes several contributions to both the resource economics and program evaluation literature. First, the policy intervention directly affected the annual fishing operations for only a subset of comparable fishing vessels, creating a natural group of control vessels that we can use to estimate the counterfactual evolution of relevant outcome variables (e.g., net revenue) for the affected vessels. To this end, we conduct a comparative case study which estimates the evolution of an outcome of interest for units (here vessels) affected by a particular intervention and compare it to the evolution of the same outcome estimated for some control group of unaffected vessels (Abadie et al., 2010). Comparative case studies for evaluating policy interventions are relatively rare in the fisheries economics literature due to the frequent lack of unaffected and comparable units for constructing a counterfactual.

Second, we are able to estimate the economic impacts of the spatial closure using a unique confidential dataset of annual fishing revenues and costs. Extensive cost data are rarely collected from the fishing industry. Indeed, most ex post policy evaluations resort to using proxies for net impacts, such as gross revenues, harvests, or welfare estimates from random utility models. Our unique dataset allows us to estimate net impacts using a measure of net revenues-a combination of fishing revenues and variable costs associated with fishing operations.

Third, we employ empirical methods that allow us to relax some of the limiting features of traditional methods for conducting comparative case studies, such as the standard difference-in-differences (DnD) estimator. In particular, we estimate the average treatment effect on the treated (ATT) of the spatial closure using propensity-score-weighted (PSW) difference-in-differences (Heckman et al., 1997; Hirano et al., 2003), which more closely balances the treated and control groups based on pre-intervention characteristics and initial conditions, and the synthetic control method (SCM) (Abadie and Gardeazabal, 2003; Abadie et al., 2010), which allows for vessel-specific comparison (or synthetic) units and the effects of unobserved vessel-specific factors to vary with time. Importantly, both the PSW and the SCM are transparent and datadriven processes for constructing a comparison group and easily allow the researcher to explore whether the comparison group is sufficiently similar to the treated group for causal inference, a feature that is obscured in the difference-in-differences model (Abadie et al., 2014).

\footnotetext{
${ }^{1}$ Some notable exceptions of comparative case studies for evaluating fishery policy interventions include Scheld et al. (2012) and Kroetz et al. (2015). Other comparative case study examples in fisheries for evaluating non-policy shocks include Abbott and Wilen (2010) and Jardine et al. (2014).
} 
Finally, we decompose the overall effect of the spatial closure on net revenue using a mediation analysis to identify the mechanisms through which the treatment impacts the treated units (Baron and Kenny, 1986; Heckman and Pinto, 2015). To accomplish this, we use a structural equation model (SEM) to trace out the paths through which the spatial closure affects net revenue (Sobel, 1987), decomposing the overall effect into multiple mechanisms. By doing so, we are able to identify what the causal impacts would have been had the marine reserve been implemented in a different institutional and/or biological setting, a feature that is critical for extrapolating results to other settings. Despite the importance for evidencebased policy making, there are relatively few examples of decomposing the overall treatment effect into causal mechanisms in the economics literature (Ferraro and Hanauer, 2014).

Our results indicate that there is minimal evidence of an overall negative effect of the spatial closure on the net revenue of affected vessels, a finding that is consistent across all modeling approaches. However, our decomposition of the overall treatment effect demonstrates that the spatial closure influences net revenue through multiple counteracting mechanisms: a negative "quota mechanism," which arises from a reduction in the harvest quotas associated with the closed area; a negative "displacement mechanism," which arises from displacing vessels from historically productive fishing grounds; and a positive "value mechanism," which arises from the ability of vessels to shift their production activities to increase the gross value of their production. These results confirm the common verdict in the literature: that the short-run cost of a marine reserve will depend on the opportunities outside of the closure (Smith et al., 2010 and citations within). In our case, opportunities to shift fishing operations to target other valuable species outside of the closure, whose quotas were either nonexistent or previously not exhausted, are critical for offsetting the costs associated with displacing vessels from their historical fishing grounds. More generally, our work demonstrates that under certain conditions, environmental protection may be considerably less costly in the short-run than ex-ante analyses suggest.

\section{Background}

\subsection{Steller sea lion closures}

Steller sea lions (Eumetopias jubatus) inhabit the North Pacific Ocean, ranging from northern Japan to central California. The western stock of SSL (hereafter any reference to "SSL" refers to the western stock) is mainly found in the Central and Western Gulf of Alaska (GOA) and the Aleutian Islands (AI; Fig. 1). The U.S. National Marine Fisheries Service (NMFS) has employed some form of protective measures for SSL conservation in the AI since the late 1980s. In 1990, the SSL was listed as "threatened" under the U.S. Endangered Species Act (ESA) as a result of a steep decline in the population starting in the late 1970s (see Berman, 2008). Due to continued declines, the SSL was eventually declared "endangered" in 1992 (National Oceanic and Atmospheric Administration, 1997). The current scientific understanding of the decline in the SSL population suggests that fishery removals of SSL prey species could thwart the recovery of the SSL population. The SSL prey on the primary species targeted by the commercial fisheries in the AI (Atka mackerel and Pacific cod) and the decline in the SSL population coincided with a sharp increase in commercial fishing for groundfish in the North Pacific in 1976 (National Oceanic and Atmospheric Administration, 2014). The federally-managed groundfish fisheries off Alaska are some of the Nation's most important in terms of quantity of fish caught and value of products produced-a significant portion of which takes place in waters adjacent to the AI, particularly for species such as Atka mackerel, Pacific ocean perch, and Pacific cod. ${ }^{2}$

Historically, protective measures for SSL conservation have included spatial closures that restrict groundfish fisheries in areas near SSL critical habitat (e.g., haulouts, rookeries, and foraging areas; Fig. 1); special harvest control rules, whereby pollock, Atka mackerel, or Pacific cod fisheries are closed if biomass falls to a certain proportion of its unfished level; and seasonal and spatial apportionment of the TACs (National Oceanic and Atmospheric Administration, 2002). In particular, the TACs for both Atka mackerel and Pacific ocean perch are delineated into three large regions in the AI: Western (543), Central (542), and Eastern (541).

In 2010, NMFS completed an ESA Section 7 consultation on the effects of the Alaska groundfish fisheries on the SSL population and on its designated critical habitat. Based on the best available information, the consultation resulted in a biological opinion that previously-implemented SSL protection measures could not ensure that the groundfish fisheries would not jeopardize the continued existence of the SSL population (National Oceanic and Atmospheric Administration, 2010). As a result, additional protection measures were placed on groundfish fishing in the Western AI in an attempt to protect the SSL population.

The 2011 protection measures, henceforth called "the closure", closed management area 543 and critical habitat areas in management area 542 to Atka mackerel and Pacific cod fishing (Fig. 1), effectively creating a large marine reserve that prohibited certain fishing activities. In addition, the closure sharply reduced the overall TAC for Atka mackerel in areas 542 and 543 (Fig. A-I in the Appendix). ${ }^{3}$ The Atka mackerel fishery primarily consists of one fleet of catcher processor (CP) trawlers that receives quota shares to over $80 \%$ of the AI Atka mackerel TAC under the Amendment 80 (A80) program.

\footnotetext{
${ }^{2}$ Catch from the federally-managed groundfish fisheries off Alaska totaled 2.3 million tons and $\$ 933.4$ million in ex-vessel value in 2014 (Fissel et al., 2015), and accounted for 53\% and 17\%, respectively, of the total weight and ex-vessel value of U.S. domestic landings in 2014 (National Marine Fisheries Service, 2016).

${ }^{3}$ Critical habitat $(\mathrm{CH})$ areas represent 20 nautical mile $(\mathrm{nm})$ buffer zones around all major SSL haulouts and rookeries in the AI. The retention ban within $\mathrm{CH}$ areas in management area 542 after 2011 was comprehensive, except for a small area of $\mathrm{CH}$ (between 10 and $20 \mathrm{~nm}$ ) between $179^{\circ}$ and $178^{\circ}$ longitude.
} 


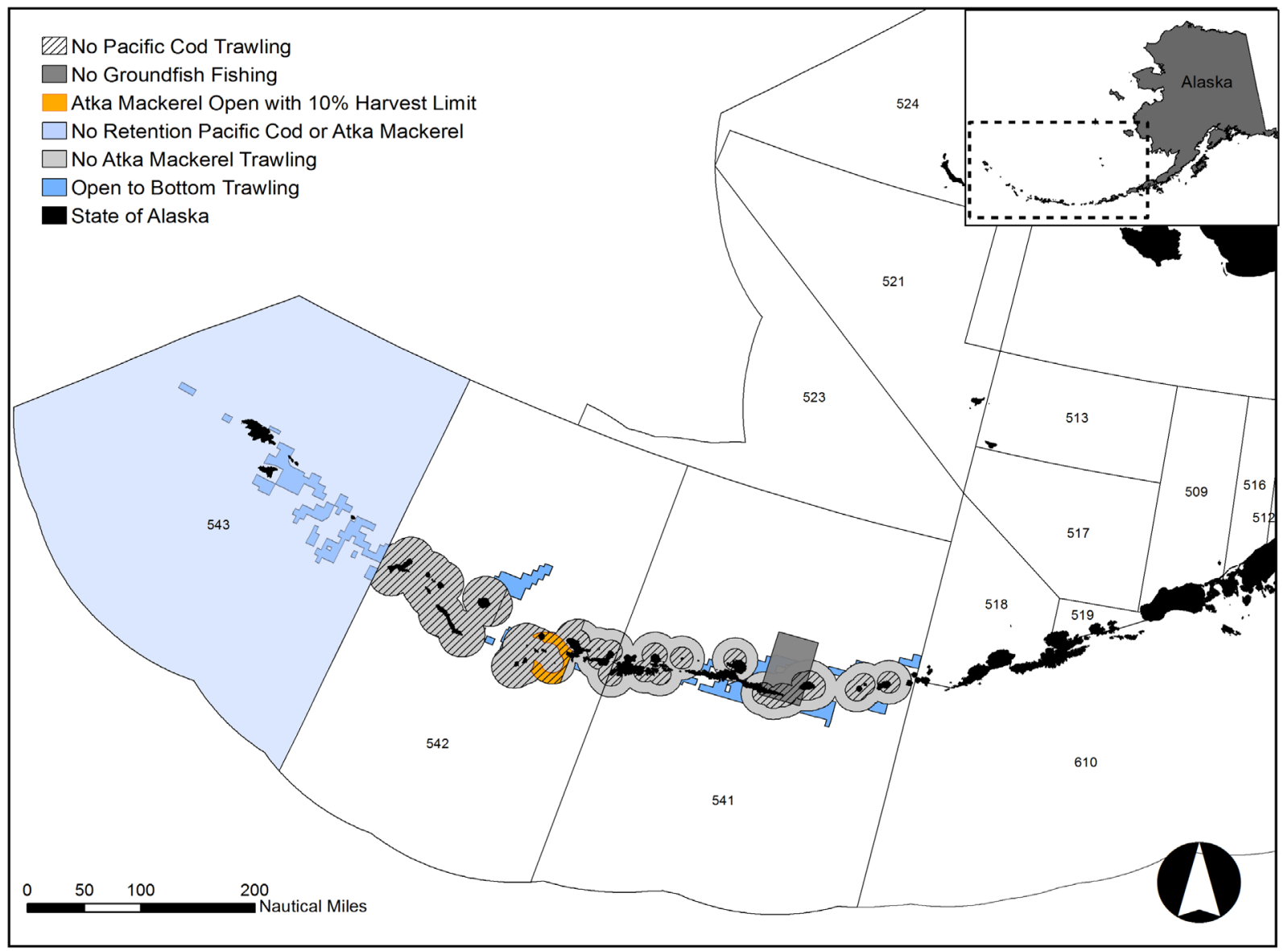

Fig. 1. National Marine Fisheries Service management areas for the Bering Sea and Aleutian Islands and the spatial closures in place for the Pacific cod and Atka mackerel trawl fisheries from 2011 to 2014.

Between 2008 and 2010, seven CP trawlers harvested an annual average of 61,000 metric tons (mt) of Atka mackerel (US $\$ 61.6$ million wholesale) in the AI, of which approximately 25\% took place in management area 543 (National Oceanic and Atmospheric Administration, 2014). Pacific cod fisheries in the AI, on the other hand, are prosecuted by a variety of different vessel types: A80 CP trawlers, non-trawl (hook-and-line and pot) CPs, trawl catcher vessels (CVs), and non-trawl (hook-andline, pot, and jig) CVs. Between 2008 and 2010, approximately 24,000 mt of Pacific cod (US\$24.1 million wholesale) was harvested in the AI, on average, of which $14 \%$ was harvested by 11 trawl CPs, 29\% by 13 non-trawl CPs, and $57 \%$ by 22 trawl CVs (National Oceanic and Atmospheric Administration, 2014). ${ }^{4}$ Altogether, the closure was estimated to put US\$27-47 million in gross wholesale revenues "at risk" (annually) for the A80 trawl CPs, US\$11-14 million for the non-trawl CPs, and \$9-12 million for the trawl CVs (National Oceanic and Atmospheric Administration, 2014).

\subsection{The amendment 80 fleet}

For our evaluation, we focus only on the $\mathrm{CP}$ trawlers in the A80 program for the following reasons: $i$ ) the $\mathrm{CP}$ trawlers were the dominant fleet across the affected AI groundfish fisheries (particularly Atka mackerel), in terms of both harvests and wholesale revenues, with a significant portion of fishing activity taking place in area 543 prior to 2011; $i$ ) in contrast to the other fleets, the A80 CP trawlers have had complete onboard observer coverage since 2008, giving us a comprehensive dataset of all fishing activity for all vessels that participate in the A80 program ${ }^{5}$; iii) unlike the other fleets, all A80 participants must submit an Economic Data Report on an annual basis, providing a unique dataset comprised of vessel-level annual revenue and costs derived from vessel activity in the North Pacific groundfish fisheries; and $i v$ ) since only a portion of the vessels in the A80 fleet targeted Atka mackerel and Pacific cod in the AI, the A80 fleet provides a unique opportunity

\footnotetext{
${ }^{4}$ Less than $0.1 \%$ of the total harvest Pacific cod in the AI is attributed to the non-trawl CVs during this period.

${ }^{5}$ Under the North Pacific Groundfish Observer Program, onboard observers record the deployment and retrieval location and times for every trawl, as well as additional information such as the total catch and tow depth. Observers also randomly select hauls for species composition sampling. See http:// www.afsc.noaa.gov/FMA/default.htm for more information.
} 
to form a counterfactual (or control group) for the vessels that were required to halt fishing for Atka mackerel and Pacific cod in area 543 after 2011.

A80 CPs use non-pelagic ("bottom") trawl gear to target groundfish in the federal waters of the United States North Pacific. ${ }^{6}$ Vessels in the A80 fleet embark on trips of 1-2 weeks in length, processing harvested fish onboard. Processing is typically minimal, usually involving "heading and gutting" the fish, freezing them, and delivering them to brokers or wholesalers for direct sale or further processing. Since the early 2000 s, the fleet has had twenty-three participating vessels. ${ }^{7}$ The fleet's name signifies the passage of Amendment 80 to the Bering Sea/Aleutian Islands (BSAI) Groundfish Fishery Management Plan, which was implemented in 2008. The provisions of A80 were intended to facilitate increased target catch and profits, reduce bycatch and discards, and increase flexibility while complying with target and prohibited species TACs. A80 resulted in two major changes to fishery regulations. First, A80 granted a share of the total A80 TAC for the six primary target species (yellowfin sole, rock sole, flathead sole, Pacific cod, Atka mackerel, and Pacific ocean perch) to each vessel based on its catch history. Second, vessels could either vest their shares in a cooperative formed by participating members or participate in a limited-access fishery. Cooperatives are given considerable flexibility as to how quotas are allocated among members. Leasing arrangements and/or non-arm's-length methods of reallocation within the cooperative are all feasible, and trading between cooperatives is allowed. Vessels that chose to participate in the limited-access fishery had a share of their historic proportion of target species put in a common pool that is available to all vessels in the limited-access fishery, similar to pre-A80 management. In addition, cooperatives receive shares of "prohibited species catch" (PSC) TACs according to their holdings of target species, and all vessels in the limited access fishery share the same overall PSC caps based on a proportion of catch history of vessels in the limited access fishery. In practice, companies have primarily fished their own target and PSC allocations, although recently there have been sales and more frequent exchanges of quota of one species for another between companies. ${ }^{8}$

Immediately following the implementation of $A 80$, a subset of the fleet (sixteen vessels, seven companies) formed a single cooperative (Alaska Seafood Cooperative, hereafter ASC), while the remaining seven vessels (three companies) elected to remain in the limited-access sector. In 2011, all vessels in the limited-access sector formed a second cooperative (Alaska Groundfish Cooperative, hereafter AGC), eliminating the limited-access sector. There has been some consolidation in the fleet since the implementation of A80. In 2011, sixteen CPs (five companies) actively fished as part of ASC, while only four vessels (one company) actively fished as part of AGC.

\section{Methods}

To evaluate the impacts of the closure for protecting the SSL population, we conduct a comparative case study, which estimates the evolution of an outcome for vessels affected by the closures and compare it to the evolution of the same outcome estimated for a control group of unaffected vessels (e.g., Card, 1990; Card and Krueger, 1994). Central to our identification strategy is the fact that the closure interfered in the annual fishing plans of only a subset of the vessels in the A80 fleet-namely those vessels that targeted Atka mackerel and Pacific cod in the AI prior to $2011 .{ }^{9}$ Of the ten vessels that caught and retained Atka mackerel and Pacific cod in the AI prior to 2011, seven actively targeted these species in area 543, the area in which fishing was most restricted by the 2011 closure (Table A-I in the Appendix). Indeed, these seven vessels spent $15 \%$ of their effort (measured in trawling hours) in area 543 prior to 2011 in comparison to $<0.1 \%$ for the remaining thirteen A80 vessels (Table 1). Moreover, these seven vessels harvested $98 \%$ of all Atka mackerel caught by A80 vessels in the AI prior to 2011, with Atka mackerel comprising 43\% of their per-vessel wholesale revenues, on average. In contrast, Atka mackerel accounted for an average of only $0.7 \%$ of wholesale revenues for the remaining A80 vessels (Table 1 ). Thus, the seven vessels actively targeting Atka mackerel and Pacific cod in area 543 prior to 2011 were exposed to the closure by a distinctly greater degree, and therefore serve as the "treated" group for our analysis. Our "control" group consists of the eleven A80 vessels that did not target Atka mackerel and Pacific cod in area 543 and also fished in all years of the sample. ${ }^{10}$

\subsection{Data}

We use a combination of confidential and publicly available data sets for our analysis. Confidential data comes from

\footnotetext{
${ }^{6}$ The A80 fleet is comprised of vessels that have historically caught groundfish other than pollock, such as flatfish (e.g., rock sole, yellowfin sole, flathead sole), Atka mackerel, and Pacific ocean perch.

7 Originally, 28 CP vessels were eligible for the A80 program. However, three of these vessels have sunk (including one in 2008, after Amendment 80 was implemented), and three others have not fished in Alaska since 2003 (Northern Economics, 2014). Since 2013, 18 vessels have participated in the fishery.

${ }^{8}$ A company's total catch for each target and prohibited species rarely exceeds its allocated quota (not shown due to confidentiality), suggesting that companies primarily fish their own target and PSC allocations.

${ }^{9}$ Abbott and Wilen (2010) follow a similar identification strategy for the same fleet to estimate the effects of a voluntary program for bycatch reduction starting in 1995.

${ }^{10}$ Note that two A80 vessels participated in at least one but not all years of the sample, and are thus not considered in this analysis out of concern that the lack of full participation compromises their comparability to the vessels in the treatment group. Including these vessels does not meaningfully change our results.
} 
Table 1

Descriptive statistics for the control and treated groups.

\begin{tabular}{|c|c|c|c|c|c|c|c|c|c|}
\hline Variable & Group & Area/Species & 2008 & 2009 & 2010 & 2011 & 2012 & 2013 & 2014 \\
\hline \multirow[t]{2}{*}{ Active Vessels } & Control & & 15 & 14 & 13 & 13 & 13 & 11 & 11 \\
\hline & Treated & & 7 & 7 & 7 & 7 & 7 & 7 & 7 \\
\hline \multirow[t]{2}{*}{ Average Number Days Fished } & Control & & 175 & 171 & 171 & 165 & 156 & 155 & 164 \\
\hline & Treated & & 210 & 184 & 205 & 225 & 233 & 239 & 253 \\
\hline \multirow[t]{2}{*}{ Average Annual Quota (1000 mt) } & Control & & 13.7 & 14.6 & 15.0 & 13.3 & 13.0 & 12.3 & 11.9 \\
\hline & Treated & & 22.6 & 23.8 & 24.6 & 20.5 & 20.0 & 18.5 & 18.2 \\
\hline \multirow[t]{2}{*}{ Allocated Quota Harvested (\%) } & Control & & 80.3 & 67.9 & 77.4 & 80.4 & 85.9 & 88.5 & 80.7 \\
\hline & Treated & & 67.7 & 59.0 & 52.3 & 60.5 & 61.2 & 59.0 & 65.6 \\
\hline \multirow[t]{10}{*}{ Average Fishing Time (\%) } & Control & Aleutian Islands 541 & 1.2 & 4.1 & 5.6 & 3.4 & 6.9 & 1.5 & 0.2 \\
\hline & & Aleutian Islands 542 & 0.0 & 0.7 & 0.0 & 0.0 & 0.0 & 0.0 & 0.0 \\
\hline & & Aleutian Islands 543 & 0.0 & 0.0 & 0.0 & 0.0 & 0.0 & 0.0 & 0.0 \\
\hline & & Bering Sea & 93.7 & 90.6 & 88.7 & 89.5 & 89.0 & 91.2 & 87.2 \\
\hline & & Gulf of Alaska & 16.6 & 12.2 & 12.0 & 13.1 & 10.8 & 11.4 & 23.4 \\
\hline & Treated & Aleutian Islands 541 & 7.3 & 15.7 & 20.9 & 28.5 & 40.5 & 28.6 & 21.6 \\
\hline & & Aleutian Islands 542 & 13.5 & 13.8 & 14.3 & 7.3 & 7.6 & 6.6 & 5.4 \\
\hline & & Aleutian Islands 543 & 12.8 & 16.6 & 16.0 & 6.3 & 6.4 & 5.9 & 4.8 \\
\hline & & Bering Sea & 61.1 & 48.4 & 43.5 & 55.6 & 42.9 & 57.4 & 65.5 \\
\hline & & Gulf of Alaska & 5.2 & 5.6 & 5.3 & 4.1 & 4.4 & 3.3 & 4.9 \\
\hline \multirow[t]{12}{*}{ Average Wholesale Revenue (\%) } & Control & Atka Mackerel & 0.6 & 1.2 & 0.9 & 0.6 & 1.9 & 1.3 & 1.0 \\
\hline & & Flathead Sole & 11.4 & 8.2 & 8.7 & 4.1 & 2.9 & 9.5 & 6.0 \\
\hline & & Pacific Cod & 14.9 & 14.8 & 14.2 & 13.4 & 11.7 & 13.4 & 12.4 \\
\hline & & Pacific ocean Perch & 1.2 & 2.3 & 4.0 & 5.4 & 4.7 & 4.1 & 6.3 \\
\hline & & Rock Sole & 18.8 & 19.9 & 22.3 & 19.5 & 25.2 & 16.4 & 14.1 \\
\hline & & Yellowfin Sole & 33.6 & 31.3 & 31.8 & 31.0 & 28.3 & 29.4 & 26.0 \\
\hline & Treated & Atka Mackerel & 35.1 & 51.7 & 47.9 & 35.9 & 35.4 & 26.9 & 31.6 \\
\hline & & Flathead Sole & 1.1 & 0.7 & 0.7 & 0.5 & 0.2 & 0.9 & 0.6 \\
\hline & & Pacific Cod & 5.8 & 3.0 & 4.2 & 5.3 & 4.6 & 7.4 & 6.6 \\
\hline & & Pacific ocean Perch & 14.8 & 14.5 & 19.2 & 24.8 & 20.0 & 22.1 & 22.8 \\
\hline & & Rock Sole & 5.4 & 1.8 & 2.3 & 4.4 & 10.9 & 5.8 & 5.8 \\
\hline & & Yellowfin Sole & 27.0 & 18.7 & 14.2 & 18.0 & 16.0 & 18.5 & 14.4 \\
\hline
\end{tabular}

Economic Data Reports (EDRs), which are mandatory annual reporting requirements for all A80 participants, and provide detailed data on vessel-specific costs, earnings, employment, quota transfers, and capital improvements. ${ }^{11}$ We also use confidential data from vessel-level production reports, which provide the production weight of final products for each target species; commercial operator annual reports, which provide information on annual product prices from each vessel; and data from onboard observers. Publicly available data sets include annual vessel-specific quota allocations for each of the A80 target and bycatch species. ${ }^{12}$

We use annual net revenue as reported in the EDRs for our main outcome variable for measuring the economic impacts of the closure. We compute net revenue as annual gross revenue minus annual variable costs. Revenue includes product sales, income from other sources (e.g., tendering, scientific charters, etc.), and income from leasing quota shares to other vessels. Variable costs include (among other things) costs associated with labor, fuel, maintenance and repair, food, packaging, and fish taxes. ${ }^{13}$ As we describe in detail below, we also use the following variables as part of our mediation analysis, which explores the mechanisms through which the closure impacted affected vessels: i) the total annual amount of fish harvested; ii) the total annual amount of quota across all six target species allocated to an individual vessel at the beginning of the year; and iii) the average annual wholesale price received by each vessel. ${ }^{14}$

\subsection{Identification of causal effects}

Our primary goal is to estimate the effect of the closure on the net revenue of the A80 CP trawlers. For the estimated

\footnotetext{
${ }^{11}$ Further information regarding the EDR data collection program, including EDR forms, protocols, and results of data quality assessment and controls, is available at http://www.psmfc.org/am80edr/.

${ }^{12}$ Wholesale price data is available at http://www.afsc.noaa.gov/refm/Socioeconomics/SAFE/groundfish.php\#data. Annual quota allocations are available at https://alaskafisheries.noaa.gov/permits-licenses?field_fishery_pm_value $=$ Amendment +80 .

${ }^{13}$ For an explicit list of all the elements included in gross revenue and variable cost, see Tables 3 and 5, respectively, in the EDR forms at http://www. psmfc.org/am80edr/. Due to the lumpy inter-annual nature of capital expenditures, such as those associated with gear and processing equipment (Table 4 of EDR), we exclude them when calculating net revenue.

${ }^{14}$ Average wholesale price is computed as the sum of annual production values over all species (i.e., production weight (mt) times product price $(\$ / \mathrm{mt})$ ) divided by the annual production weight $(\mathrm{mt})$.
} 
(a) Selection bias

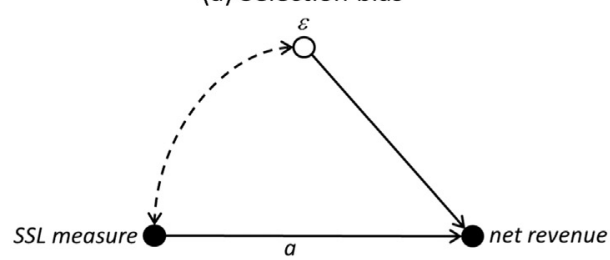

(b) Mechanisms

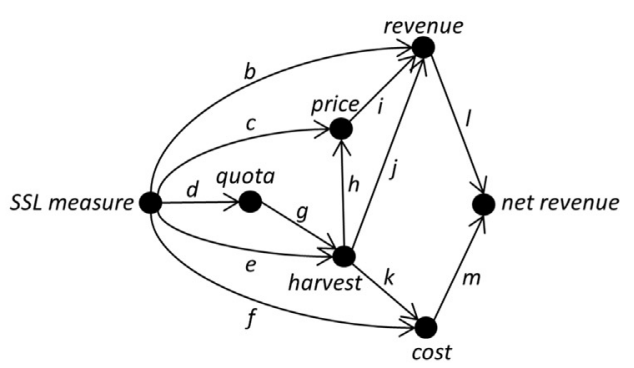

Fig. 2. Causal diagram of: a) the overall treatment effect (closure) on the outcome variable (net revenue) and b) the mechanisms through which closure causes net revenue. Note: The directed edge $x \rightarrow y$ signifies that $x$ causes $y$ while the bidirected edge $x \leftrightarrow y$ signifies that $x$ and $y$ are mutually dependent (Morgan and Winship, 2014). Solid nodes represent observed variables while hollow nodes represent unobserved variables.

effect to be interpreted as causal, care must be taken to address concerns over selection bias-i.e., the concern that vessels targeting Atka mackerel and Pacific cod in area 543 prior to the closure are fundamentally different from those that did not in ways that also influence changes in net revenue over time. Generally speaking, selection bias problems arise from the existence of a "back-door path" between the treatment variable (closure) and the outcome variable (net revenue), as depicted in the directed acyclic graph in Fig. 2a, where the directed edge $x \rightarrow y$ signifies that $x$ causes $y$ (Pearl, 1995). As drawn, the causal effect closure $\rightarrow$ net revenue (edge $a$ ) is confounded by the "back-door path" closure $\leftarrow \varepsilon \rightarrow$ net revenue since the unobservable variable $\varepsilon$ influences both net revenue and closure. For example, we would expect that treated vessels differ in many ways that also influence net revenue-on average, they tend to be significantly larger, have more quota, specialize in targeting groundfish species in the Aleutian Islands, and have particular types of skill, experience, and knowledge, including awareness of markets for Atka mackerel. In general, there are many potential strategies for isolating the causal effect from the confounding influences of an unobserved variable $\varepsilon$. For instance, when selection is based on observable variables, selection bias can be addressed by conditioning on variables that satisfy the "back-door criterion" (e.g., regression or matching methods). If instead selection is based on unobservable variables, other strategies that do not rely on conditioning can be used, such as instrumental variables or difference-in-differences (Angrist and Pischke, 2009; Morgan and Winship, 2014).

We use a variety of estimation procedures for identifying the causal effect of the spatial closure on the treated vessels, including difference-in-differences (DnD), propensity-score-weighted (PSW) differences-in-differences, and the synthetic control method (SCM). The key identifying assumption for our analysis is that the confounding variable $\varepsilon$ in Fig. 2a can be broken up into the following four components: a vector of observable variables $X$ that vary over time and vessel and cause both net revenue and the treatment assignment; an unobservable vessel-specific and time-invariant variable $\phi$ that causes both net revenue and the treatment assignment (e.g., skill, expertise, historical fishing patterns, etc.); an unobservable timevarying factor $\theta$ that influences the net revenue equally across all vessels (e.g., global markets, regulations, sea ice patterns, etc.); and an unobservable variable $\nu$ that varies over time and vessel and directly impacts only net revenue and not the treatment assignment. This latter assumption is the key identifying assumption for isolating the effect of the closure on net revenue as it allows us to block the "back-door path" closure $\leftarrow X, \phi, \theta \leftrightarrow v \rightarrow$ net revenue by conditioning on $X$ and "differencing away" $\phi$ and $\theta .^{15}$

There is good reason to believe that the above identifying assumption is satisfied for our case study. The vessels in both the treated and control groups are comparable: they use bottom trawl gear, they are catcher processors, nearly all their products are in either headed and gutted form or whole fish (Fig. A-II), they have quota for many (but not all) of the same species (Fig. A-III), they fish in many of the same areas (Table 1), and are subject to the same regulatory restrictions. However, as noted above, the treated vessels also differ from those in the control group in other ways: they are larger, they have more output quota with compositions that are more heavily concentrated in Atka mackerel and Pacific ocean perch rather than flatfish, and they pursue different targeting strategies-e.g., they spend more time targeting Atka mackerel in the AI (Table 1). These differences, however, do not necessarily violate the assumptions necessary for the treatment effect estimator to be unbiased. In particular, unbiasedness requires that the trends in net revenue be the same in the absence of the treatment (Angrist and Pischke, 2009). ${ }^{16}$ Time series for the multiple outcomes of interest in our evaluation provide some evidence that the common trend assumption is satisfied (Fig. 3), suggesting that many of the differences between the

\footnotetext{
${ }^{15}$ Note that the SCM is more flexible than the DnD and PSW approaches as it allows the effects of unobserved vessel-specific factors to vary with time (Abadie et al., 2010).

${ }^{16}$ This is often referred to as the "common trends" assumption (Angrist and Pischke, 2009). Note that this assumption can be relaxed to allow for group-specific trends (Blundell and MaCurdy, 1999).
} 

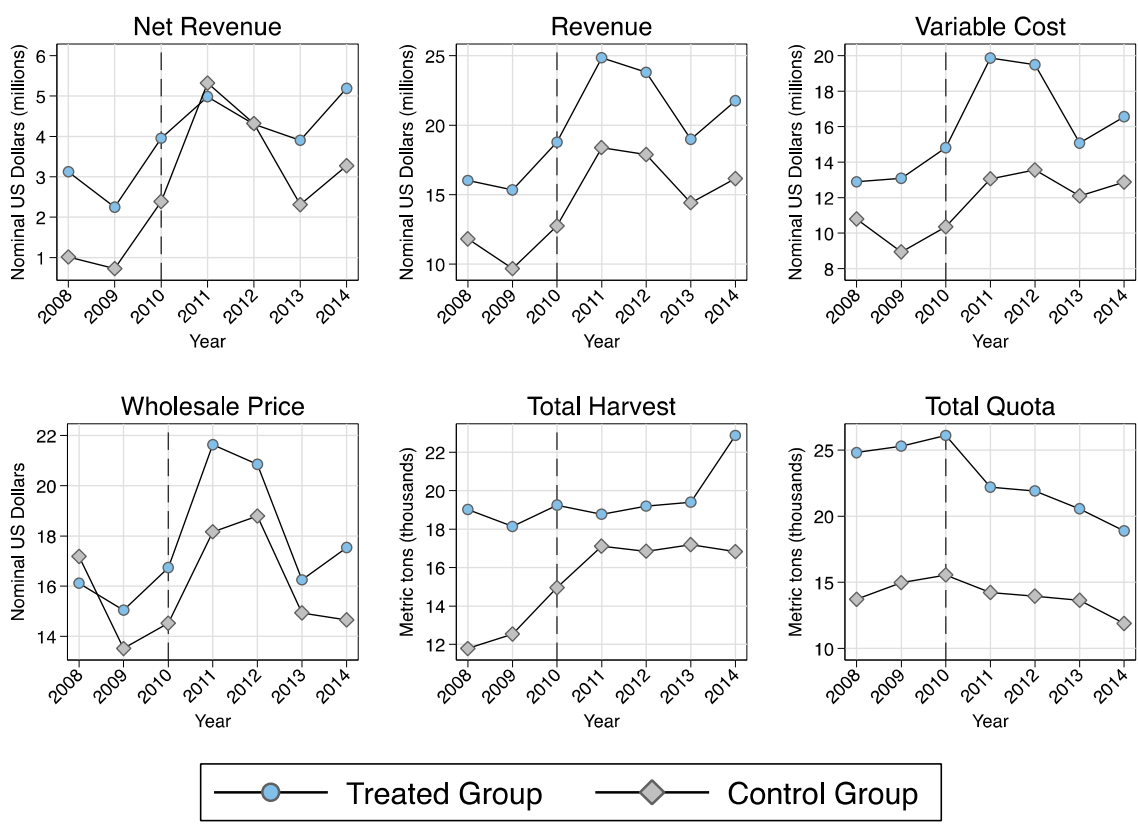

Fig. 3. Average outcome variables for the treated and control vessels, 2008-2014.

treated and the control units are likely captured by the time-invariant vessel effects $\phi \cdot{ }^{17}$ One notable exception, however, is that because the treated group is more specialized in Atka mackerel and Pacific ocean perch, any exogenous shock to the price or TAC of these species at the time of the closure would likely confound our estimate of the treatment effect. We discuss this issue further, along with a possible way to address it, below.

Our estimators rely on several other assumptions for identification. First, the composition of both the treatment and control groups must remain stable before and after the policy change or there exists the possibility of bias from vessels selfselecting to leave the treatment or control groups in response to the policy (Blundell and MaCurdy, 1999). Our sample includes only those A80 vessels that fished before and after the closure was implemented. We assign vessels that targeted Atka mackerel to the treated group and all other A80 vessels to the control group, and these assignments remain constant across all years. Thus, the compositions of the treated and the control groups remain stable by design.

Second, the treatment should not "contaminate", or indirectly impact, the control group through spillover effects; otherwise, the control group will not serve as a good representation of the counterfactual outcomes for the treated units in the absence of the policy change. One potential source of contamination resulting from the closure is congestion-related effects from increased fishing effort in the Bering Sea as treated vessels shifted effort towards other directed fisheries, such as yellowfin and rock sole. Indeed, if increased fishing effort in the Bering Sea resulted in any negative congestion-related effects on the control units, in terms of crowded fishing grounds or local stock depletion, then the magnitude of our estimator will be biased downwards. Given the enormous size of the Bering Sea, it may seem unlikely for there to be any congestion effects arising from any increased fishing effort of seven vessels; however, targeted species are not uniformly distributed across space, and many have relatively concentrated distributions in particular areas and seasons (e.g., rock sole). Another potential source of contamination stems from the transferability of quota across vessels: if the closure induced treated vessels to change their quota leasing patterns, perhaps to generate additional revenue to offset the cost of the closure, then this could directly impact control vessels through increased exchange of quota. ${ }^{18}$ We explore the possibility of contamination via congestion and quota transfers in Section 4.3, and conclude that spillover effects are likely small and inconsequential for our results.

\footnotetext{
${ }^{17}$ We are conscious of the fact that having only three pre-intervention years is not ideal for supporting our claim of parallel trends; however, we are limited by the fact that our main outcome variable net revenue is constructed using information from the EDRs, which were not collected until 2008 Fortunately, we do have time series for several relevant intermediary outcome variables-i.e., wholesale revenue, harvest, and wholesale price-that go back to 1992, and can therefore be used to shed light on whether our parallel trend assumption is valid. Fig. A-IV shows that treated-and control-group averages for the intermediary variables do in fact move in parallel fashion, giving us some confidence that any differences between the treated and control groups that differentially affect our outcome variables can be largely captured by time-invariant fixed effects. This finding is further supported by the fact that we cannot reject (at the 10\% level) the null hypothesis that each intermediary variable followed the same linear time trend between 1992 and 2010 . See Appendix B.1. for details.

${ }^{18}$ We thank an anonymous referee for pointing this out.
} 


\subsection{Causal mechanisms}

Even if our estimation strategy suggests that the protective measures had a causal effect on treated vessels' net revenue, however, it does not tell us how or why. This is relevant for our case study given that there are multiple mechanisms through which closure can influence treated vessels' net revenue (Fig. 2b). The closure directly reduced the amount of quota allocated to the treated vessels (edge $d$ ) by substantially reducing the TACs for Atka mackerel in management areas 542 and 543 (Fig. A-I). ${ }^{19}$ If a reduction in quota leads to reduced harvest (edge $g$ ), then quota will likely have a negative indirect effect on net revenue through reduced harvest and revenue (edges $j$ and $l$ ), and a positive indirect effect on net revenue through cost due to reduced harvesting and production costs (edges $k$ and $m$ ). Furthermore, a reduction in quota could have a positive indirect effect on net revenue if, for example, the A80 fleet possesses a large share of the world product market so that reduced harvest leads to an improved wholesale price (edges $h, i$, and $l$ ). ${ }^{20}$ This so-called "quota mechanism" of the SSL protective measures stands in contrast to the "displacement mechanism," which affects net revenue independent of quota through the displacement of the treated vessels from their historically productive fishing grounds (Horrace and Schnier, 2010). For instance, if the Atka mackerel and Pacific cod closures push the treated vessels into less productive fishing locations, closure may have an adverse direct effect on harvest (edge $e$ ) and cost (edge f), which in turn affect net revenue directly and indirectly. The potential cost of the closure could be offset through a "value mechanism" if, for example, treated vessels can improve the average price they receive (edge $c$ ) by shifting their production to higher-valued species and/or increase their revenue (edge $b$ ) by shifting their efforts towards other activities, such as tendering and/or acting as a floating processor that accepts deliveries from smaller catcher vessels.

In recent years, greater attention has been given to identifying the causal mechanisms that underlie the overall causal effect of an intervention (e.g., Pearl, 2000). In particular, mediation analysis explores the existence of causal mechanisms by decomposing the overall causal effect (e.g., edge $a$ in Fig. 2a) into its individual components in order to explain why and how the treatment worked (e.g., Imai et al., 2011; Heckman and Pinto, 2015; Keele, 2015). Mediation analysis is important for our analysis because marine reserves are implemented in a variety of economic, biological, and institutional settings, all of which influence the degree of economic impact on the fishing industry. Understanding mechanisms here allows us to better understand the impacts of marine reserves across diverse settings. For example, separating the "displacement mechanism" from the "quota mechanism" provides insight into the potential impacts of implementing closures in management regions that do not have area-specific quotas. Further, mediation analysis allows us to address the issue of controlling for factors, such as an exogenous shock to the price or TAC of Atka mackerel or Pacific ocean perch, that may confound our overall estimate of the closure by disproportionately affecting the treated vessels at the time of the intervention. As we demonstrate below, our mediation analysis isolates the path through which the confounding factor influences net revenue, allowing us to hold this path constant and estimate the treatment effect without the influence of the confounding factor.

\subsection{The differences-in-difference estimator}

Consider the following general DnD model for an outcome variable of interest, $Y_{i t}$ :

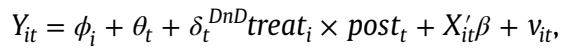

where the variable treat $t_{i}$ is a dummy variable equal to one if vessel $i$ is a member of the treated group that was exposed to the closure, post $t_{t}$ is a dummy variable equal to one if year $t$ take place after the intervention, $X_{i t}, \phi_{i}$, and $\theta_{t}$ are as defined in the previous section, and $\delta_{t}^{D n D}$ is the DnD treatment effect, which is allowed to take on distinct values for each postintervention year. $^{21}$

The DnD model provides an unbiased estimate of the average treatment effect if the unobserved selection bias is time invariant and that the control units serve as a good comparison group for the treated units. As pointed out by Abadie et al. (2014), the selection of control units is perhaps the most crucial step in comparative case studies: if control units are not sufficiently similar to the treated units, then any difference in outcomes between these two sets of units may merely reflect differences in their characteristics. Implicitly, the DnD estimator assumes that units in the control group are equally comparable to units in the treated group, on average.

We address this issue by estimating a weighted version of the DnD model in equation (1), where the weights are chosen to more closely balance the treated and control groups based on their pre-intervention outcomes, thereby creating a comparison group that is more comparable to the treated group. Our weighting scheme is based on the propensity score,

\footnotetext{
${ }^{19}$ The direct effect of $x$ on $y$ is the influence of $x$ on $y$ holding all intermediary variables between the two variables constant. Thus, the direct effect is represented by the directed arrow directly linking $x$ and $y, x \rightarrow y$., which is not intercepted by intermediaries (Pearl, 2001). In contrast, the indirect effect of $x$ on $y$ is the influence of $x$ on $y$ through intervening variables, and is represented by at least two directed arrows linking $x$ and $y$ through an intermediate variable, for example $x \rightarrow z \rightarrow y$.

${ }^{20}$ A80 harvests for many species, particularly Atka mackerel, make up a sizable portion of their respective world markets. For instance, harvests by the A80 fleet between 2011 and 2013 accounted for 25\% of the global supply for Atka mackerel, most of which ends up in Japan with few viable substitutes (Alaska Fisheries Science Center, 2015). See Fig. A-V for price trends.

${ }^{21}$ Note that by interacting treat and post in equation (1), we are identifying the annual treatment effects under the assumption that the difference in the average trend between the treated and control groups is equal to zero over the pre-intervention years.
} 
which is the predicted probability of being exposed to the treatment conditional on observed pre-intervention characteristics. As shown by Rosenbaum and Rubin (1983), the propensity score is a balancing score, in the sense that treated and control units with similar propensity scores will have a similar distribution of observed pre-intervention characteristics. Propensity-score adjustment can also address time-varying selection bias that could arise, for instance, if the evolution of net revenue is influenced by initial conditions that differ between treated and control units (Chen et al., 2009; Mu and van de Walle, 2011). To create a comparison group that more closely resembles the pre-intervention trends in net revenue of the treated group, we estimate the propensity score $P(Y)$ as a function of the annual changes in net revenue between 2008 and 2010 using a logit model. ${ }^{22}$ In turn, we follow Hirano et al. (2003) and estimate equation (1) with weights of unity for treated units and $P(Y) /(1-P(Y))$ for control units.

\subsection{The synthetic control method}

The propensity-score-weighted (PSW) DnD estimator improves the comparability of the treated and control group by balancing on observed pre-intervention outcomes. However, the PSW estimator assumes that each treated vessel has a counterfactual that can be estimated using the same comparison units, effectively assuming that changes in the outcome variable over time would have been the same for all treatment units in the absence of the intervention. In contrast, the synthetic control method (SCM) (Abadie and Gardeazabal, 2003; Abadie et al., 2010) relaxes this assumption by constructing a comparison unit for each vessel, thereby allowing for vessel-specific treatment effects. The SCM creates a synthetic control unit from a weighted average of control units, where the assigned weights are calculated to best match the synthetic control unit to the treated unit based on pre-intervention characteristics. Specifically, let the effect of the intervention for vessel $i$ in year $t$ be

$$
\alpha_{i t}=Y_{i t}^{I}-Y_{i t}^{N},
$$

where $Y_{i t}^{N}$ is the potential net revenue for vessel $i$ in year $t$ that would be observed without the intervention and $Y_{i t}^{I}$ is the potential net revenue for vessel $i$ in year $t$ that would be observed if exposed to the intervention. Let $T_{0}$ denote the period in which the intervention occurs so that vessel $i$ is exposed to the intervention in periods $T_{0}$ to $T$. Then the "treatment effects" we want to estimate are $\left(\alpha_{i, T_{0}}, \ldots, \alpha_{i, T}\right)$.

From equation (2), we know that $\alpha_{i t}=Y_{i t}^{I}-Y_{i t}^{N}=Y_{i t}-Y_{i t}^{N}$ for $t \in\left\{T_{0}, \ldots, T\right\}$, where $Y_{i t}$ is the observed net revenue. Since we don't observe the potential net revenue $Y_{i t}^{N}$ post-intervention, we need to estimate the unobserved counterfactual $Y_{i t}^{N}$ of what vessel $i$ would have experienced in the absence of the intervention in the periods $T_{0}$ to $T$ in order to obtain an estimate of the parameters of interest $\alpha_{i t}$. For the SCM approach, the estimate is a weighted average of the observed net revenue for the $J$ units in the control group:

$$
\widehat{\alpha}_{i t}=Y_{i t}-\widehat{Y}_{i t}^{N}=Y_{i t}-\sum_{\forall j \neq i} w_{i j}^{*} Y_{j t}, \quad t \in\left\{T_{0}, \ldots, T\right\}
$$

where the $w_{i j}^{*} \in \mathbf{W}^{*}$ are the time-invariant weights designated to each vessel in the control group. Intuitively, we want to choose a weighting vector $\mathbf{W}^{*}$ so that the synthetic control unit resembles the net revenue for vessel $i$ before the intervention, using potential predictors for net revenue of the donor-pool comparison units. The SCM therefore chooses the weighting matrix to minimize the distance between the pre-intervention characteristics of vessel $i$ and its synthetic control unit. ${ }^{23}$ Following the PSW model above, we use the annual changes in net revenue between 2008 and 2010 as the preintervention characteristics to determine the weighting matrix. In order to compare the estimated SCM treatment effects to those derived from the DnD and PSW models above, we follow Bohn et al. (2014) and construct a DnD estimate from our SCM treatment effects by calculating the difference between the pre-intervention averages for treated vessel $i$ and its synthetic control and subtracting this from the comparable post-intervention difference between treated vessel $i$ and its synthetic control,

$$
\widehat{\delta}_{i}^{S C M}=\frac{1}{\left(T-T_{0}+1\right)} \sum_{t=T_{0}}^{T} \hat{\alpha}_{i t}-\frac{1}{T_{0}-1} \sum_{t=1}^{T_{0}-1} \hat{\alpha}_{i t}
$$

We then use the average of $\hat{\delta}_{i}^{S C M}$ across vessels as our SCM estimate of the average treatment effect on the treated vessels. ${ }^{24}$

As discussed in Abadie et al. (2010), the SCM is a generalization of the traditional DnD model that has a number of advantages. First, SCM provides a systematic, transparent, and data-driven process for choosing comparison units, conditional on the choice of the donor pool and predictor variables. Second, SCM allows the effects of unobserved vessel-specific

\footnotetext{
${ }^{22}$ As pointed out by Abadie et al. (2014), matching on pre-intervention outcomes helps control for unobserved factors that influence year-to-year changes in net revenue, as well as any heterogeneous effects of observed and unobserved factors on net revenue.

${ }^{23}$ Additional details regarding the analytical and empirical implementation of constructing the synthetic control unit, as well as the procedure for obtaining the optimal weighting matrix $\mathbf{W}^{*}$, can be found in Abadie et al. (2010).

${ }^{24}$ In order to be consistent with the year-specific treatment effects in the DnD and PSW approaches, we also augment equation (4) to derive yearspecific treatment effects for each vessel: $\hat{\alpha}_{i t}-\left(1 / T_{0}-1\right) \sum_{s=1}^{T_{0}-1} \hat{\alpha}_{i s}$ for all $t \geq T_{0}$.
} 
factors to vary with time, thereby relaxing the "common trends" assumption in the traditional DnD model (Abadie et al., 2010). Third, the weights associated with each vessel's synthetic control make explicit the contribution of each control unit to the vessel's counterfactual of interest. Fourth, the similarities (or lack thereof) between a treated vessel and its synthetic control, in terms of pre-intervention outcomes and other predictors, is easily seen, making it explicit whether a vessel's comparison unit is sufficiently similar for causal inference. Lastly, unlike the DnD estimator, the SCM safeguards against extrapolating outside of the support of comparison units by restricting the weights for the synthetic control to be positive and sum to one (King and Zeng, 2006; Abadie et al., 2014).

Although the SCM has several attractive features relative to the DnD estimator, it is subject to many of the same assumptions necessary for unbiasedness as the DnD estimator. For example, the donor pool must be constructed of control units that are as similar as possible to the treated units, in the sense that the outcomes of interest are thought to be driven by the same structural process and not subject to structural shocks during the sample period. Further, similar to the DnD estimator, the outcomes of the control units cannot be affected, or contaminated, by the intervention.

\subsection{Mechanisms: a structural equation model approach}

The empirical methods above are useful for establishing the existence of a causal effect of the closure on net revenue, but they do not explain the source of the effect (Heckman and Smith, 1995; Imai et al., 2011). To this end, we estimate the causal mechanisms depicted in Fig. 2b using a structural equation modeling (SEM) approach, which estimates the direct effects associated with each edge using the following system of equations (Sobel, 1987):

$$
\begin{array}{ll}
\text { quota }_{i t} & =\alpha^{1}+\phi_{i}^{1}+\theta_{t}^{1}+\delta_{t}^{d} \text { treat }_{i} \times \text { post }_{t}+\varepsilon_{i t}^{1} \\
\text { harvest }_{i t} & =\alpha^{2}+\phi_{i}^{2}+\theta_{t}^{2}+\delta_{t}{ }^{e} \text { treat }_{i} \times \text { post }_{t}+\delta^{g} \text { quota }_{i t}+\varepsilon_{i t}^{2} \\
\text { price }_{i t} & =\alpha^{3}+\phi_{i}^{3}+\theta_{t}^{3}+\delta_{t}^{c} \text { treat }_{i} \times \text { post }_{t}+\delta^{h} \text { harvest }_{i t}+\varepsilon_{i t}^{3} \\
\text { cost }_{i t} & =\alpha^{4}+\phi_{i}^{4}+\theta_{t}^{4}+\delta_{t}^{f} \text { treat }_{i} \times \text { post }_{t}+\delta^{k} \text { harvest }_{i t}+\varepsilon_{i t}^{4} \\
\text { revenue }_{i t} & =\alpha^{5}+\phi_{i}^{5}+\theta_{t}^{5}+\delta_{t}^{b} \text { treat }_{i} \times \text { post }_{t}+\delta^{j} \text { harvest }_{i t}+\delta^{i} \text { price }_{i t}+\varepsilon_{i t}^{5} \\
\text { net revenue }_{i t} & \text { revenue }_{i t}-\text { cost }_{i t},
\end{array}
$$

where the parameters $\phi^{m}$ and $\theta^{m}$ denote individual and time fixed effects, respectively, for equation $m$. We make several assumptions regarding the SEM in (5) for identification purposes. First, we assume that the SEM is linear in parameters so that the direct effect corresponding to edge $n$ in Fig. $2 \mathrm{~b}$ is easily identified as the regression coefficient $\delta^{n} .{ }^{25}$ The assumption of linearity in (5) also facilitates the identification of indirect effects, which are generally not well defined in non-linear models (Pearl, 2001). Second, we assume that the SEM is recursive, in the sense that causality flows in only one directioni.e., there are no feedback loops or simultaneous relationships. ${ }^{26}$ Recursive models have the benefit of being identified as long as error terms are not correlated across equations that are directly linked (Brito and Pearl, 2002). Thus, we estimate the equations in (5) as a system, allowing for correlation between error terms while ensuring that the system is identified. Finally, we assume that the causal effect of the closure on the intermediate variables revenue, quota, harvest, price, and cost can be identified using the same DnD approach we use for net revenue, as presented in Section 3.4, which is generally supported by evidence of pre-intervention common trends for these variables (Fig. 3 and Fig. A-IV).

The estimated direct effects in the SEM in (5) can be used to compute a variety of decompositions of the overall effect of the closure. Assuming that the mechanisms depicted in Fig. 2 are exhaustive (Pearl, 2000), then we can define quota, displacement, and value mechanisms that are mutually exclusive and exhaust all possible paths of causation between closure and net revenue. This makes it possible to describe the impacts of closure on net revenue in terms of quota changes, displacement of vessels from closed areas, and changes in product value.

The effect on net revenue due to the reduction in quota-i.e., the "quota mechanism"-is equal to ${ }^{27}$ :

$$
\delta^{\text {quota }}=\underbrace{\delta^{d} \delta^{g}}_{\begin{array}{c}
\text { closure } \rightarrow \text { quota } \\
\rightarrow \text { harvest }
\end{array}} \times(\underbrace{\delta^{j}}_{\begin{array}{c}
\text { harvest } \rightarrow \text { revenue } \\
\rightarrow \text { net revenue }
\end{array}}+\underbrace{\delta^{h} \delta^{i}}_{\begin{array}{c}
\text { harvest } \rightarrow \text { price } \rightarrow \\
\text { revenue } \rightarrow \text { net revenue }
\end{array}}-\underbrace{\delta^{k}}_{\begin{array}{c}
\text { harvest } \rightarrow \text { cost } \\
\text { net revenue }
\end{array}})
$$

where $\delta^{d} \delta^{g}$ is the indirect effect of closure on harvest due to the reduction in quota, and the bracketed term is the overall

${ }^{25}$ Note that the last equation in (5) holds by definition, and thus, the direct effects associated with edges $l$ and $m$ in Fig. $2 \mathrm{~b}$ are equal to 1 and -1 , respectively.

${ }^{26}$ The recursive nature of the system of equations in (5) may be called into question, particularly with respect to the relationships harvest $\rightarrow$ price and harvest $\rightarrow$ cost. Specifically, one might expect both price and cost to also influence harvest. We explore the potential simultaneity between harvest, price, and cost in Appendix B.2. and conclude that there is little evidence to suggest that the recursive relationship between these variables does not exist.

27 The linear system of equations implies that an indirect effect, say of $x$ on $y$ through an intermediate variable $z$ for instance, is the product of the direct effects of $x$ on $z$ and $z$ and $y$, which is equal to the product of the regression coefficients associated with each direct effect. The total effect of $x$ on $y$ is thus the sum of all indirect effects and the direct effect of $x$ on $y$. 


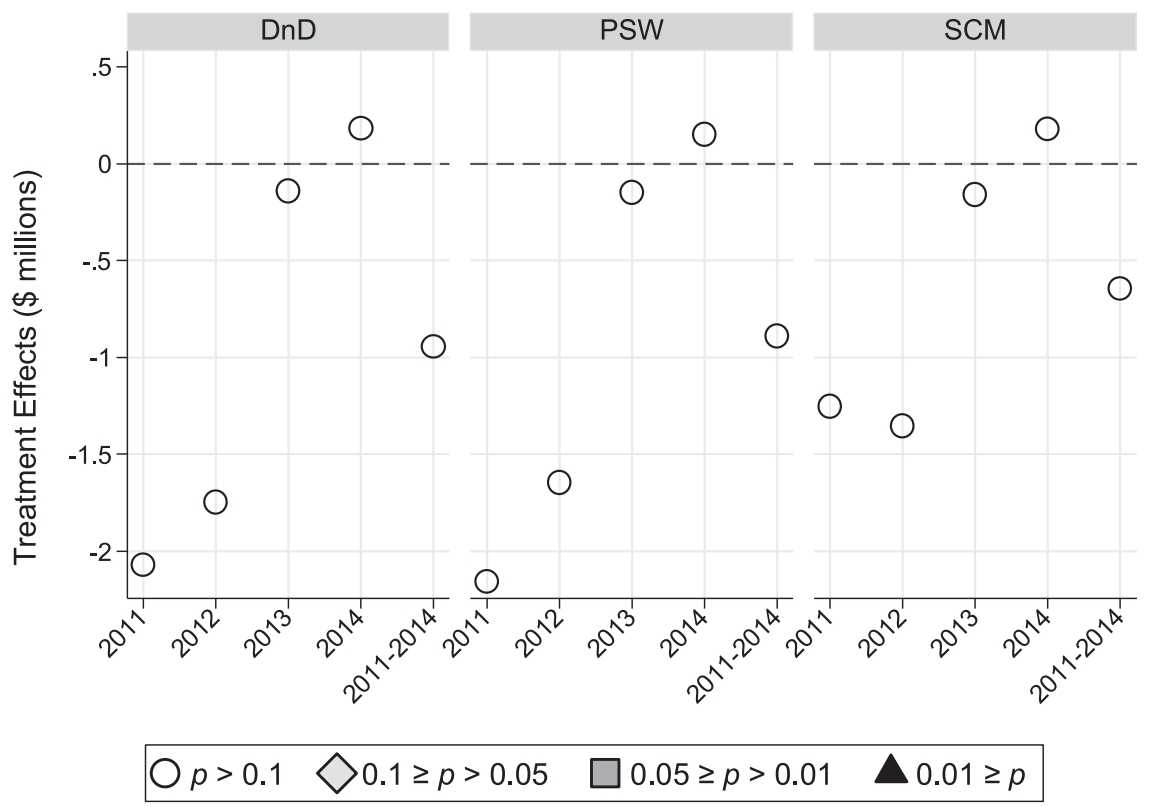

Fig. 4. Point estimates of the annual average treatment effect of closure on net revenue for the DnD, PSW, and SCM models. Note: The color and shape of the markers indicate statistical significance of estimates based on different critical p-values (p). 2011-2014 denotes the average effect across all post-intervention years.

effect of harvest on net revenue, which is comprised of three components: the indirect effect of harvest on net revenue via a change in revenue $\delta^{j}$, the indirect effect of harvest on revenue through price $\delta^{h} \delta^{i}$, and the indirect effect of harvest on net revenue through cost adjustments $\delta^{k}$. Similarly, the effect of closure on net revenue from the displacement of vessels from historically productive fishing grounds-i.e., the "displacement mechanism"-is equal to:

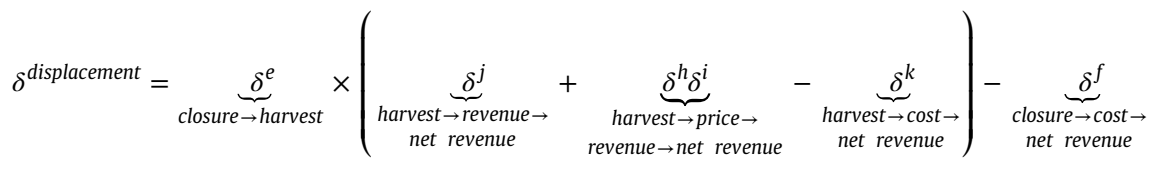

where $\delta^{f}$ is the effect of cost on net revenue induced by closure, $\delta^{e}$ is the direct effect of closure on harvest, and the bracketed term is the overall effect of harvest on net revenue (as described above). Lastly, the potentially offsetting effect of closure on net revenue from shifting production to more valuable species and/or to other revenue-generating activities-i.e., the "value mechanism"-is equal to:

$$
\delta^{\text {value }}=\underbrace{\delta^{b}}_{\text {closure } \rightarrow \text { revenue } \rightarrow \text { net revenue }}+\underbrace{\delta^{c} \delta^{i}}_{\text {closure } \rightarrow \text { price } \rightarrow \text { revenue } \rightarrow \text { net revenue }}
$$

where $\delta^{b}$ is the impact on net revenue from a direct effect of closure on revenue and $\delta^{c} \delta^{i}$ is the impact on net revenue from a direct effect of closure on price and its subsequent effect on revenue. Thus, the total effect of closure on net revenue is the sum of the quota, displacement, and value mechanisms, $\delta^{\text {quota }}+\delta^{\text {displacement }}+\delta^{\text {value }}$.

\subsection{Inference}

The use of statistical inference in comparative case studies is difficult for several reasons. First, as pointed out by Bertrand et al. (2004), DnD models estimated with long panel datasets typically suffer from severe serial correlation, resulting in standard errors that are too small if serial correlation is neglected. Second, comparative case studies often rely on a relatively small number of treated and control units, making estimators that rely on cross-section asymptotics infeasible as inferential techniques. Finally, as argued by Abadie et al. (2010), statistical inference techniques based on uncertainty arising from sampling error are irrelevant for case studies such as this one that have the entire population of aggregate data.

For all the models above, we use permutation-based inferential techniques, which are based upon uncertainty regarding whether the control group is able to reproduce the counterfactual outcome that the treated unit would have exhibited in the absence of the intervention (Abadie et al., 2010). ${ }^{28}$ For example, we would lose confidence that a sizable estimate of the

\footnotetext{
${ }^{28}$ Estimation of all models was conducted in Stata SE 14.0 (StataCorp LP, College Station, Texas). Permutation-based p-values were computed using
} 
Table 2

SCM results and weights for each treated vessel in the trimmed sample.

\begin{tabular}{|c|c|c|c|c|c|c|c|}
\hline & & Vessel 1 & Vessel 2 & Vessel 3 & Vessel 4 & Vessel 5 & Vessel 6 \\
\hline \multirow[t]{3}{*}{$2011-2014$} & Treatment Effect & -1.32 & 0.76 & -0.43 & -1.43 & -0.49 & -0.97 \\
\hline & p-value & 0.17 & 0.67 & 0.33 & 0.00 & 0.33 & 0.17 \\
\hline & rank & 3 & 9 & 5 & 1 & 5 & 3 \\
\hline \multirow[t]{3}{*}{2011} & Treatment Effect & 0.91 & -0.98 & -10.52 & 0.70 & 1.63 & 0.73 \\
\hline & p-value & 0.50 & 0.33 & 0.00 & 0.50 & 0.50 & 0.50 \\
\hline & rank & 7 & 5 & 1 & 7 & 7 & 7 \\
\hline \multirow[t]{3}{*}{2012} & Treatment Effect & -4.15 & 2.26 & 2.68 & -5.68 & -0.31 & -2.91 \\
\hline & p-value & 0.00 & 0.75 & 0.92 & 0.00 & 0.25 & 0.00 \\
\hline & rank & 1 & 10 & 12 & 1 & 4 & 1 \\
\hline \multirow[t]{3}{*}{2013} & Treatment Effect & -1.19 & -0.53 & -1.82 & 1.54 & 0.27 & 0.79 \\
\hline & p-value & 0.25 & 0.25 & 0.25 & 0.67 & 0.58 & 0.58 \\
\hline & rank & 4 & 4 & 4 & 9 & 8 & 8 \\
\hline \multirow[t]{3}{*}{2014} & Treatment Effect & -0.85 & 2.29 & 7.94 & -2.30 & -3.54 & -2.48 \\
\hline & p-value & 0.33 & 0.83 & 0.92 & 0.25 & 0.00 & 0.25 \\
\hline & rank & 5 & 11 & 12 & 4 & 1 & 4 \\
\hline \multirow[t]{11}{*}{ Weights } & Vessel 7 & 0 & 0 & 0 & 0 & 0 & 0.102 \\
\hline & Vessel 8 & 0.294 & 0 & 0 & 0.676 & 0.216 & 0.03 \\
\hline & Vessel 9 & 0 & 0 & 0 & 0 & 0 & 0.073 \\
\hline & Vessel 10 & 0.706 & 0.594 & 0 & 0 & 0.784 & 0.267 \\
\hline & Vessel 11 & 0 & 0 & 0 & 0 & 0 & 0.047 \\
\hline & Vessel 12 & 0 & 0 & 0 & 0 & 0 & 0.079 \\
\hline & Vessel 13 & 0 & 0 & 0 & 0 & 0 & 0.086 \\
\hline & Vessel 14 & 0 & 0 & 0 & 0 & 0 & 0.161 \\
\hline & Vessel 15 & 0 & 0 & 0.829 & 0.324 & 0 & 0.026 \\
\hline & Vessel 16 & 0 & 0.406 & 0.171 & 0 & 0 & 0.094 \\
\hline & Vessel 17 & 0 & 0 & 0 & 0 & 0 & 0.036 \\
\hline \multicolumn{2}{|c|}{ Pre-intervention Fit } & 0.179 & 0.563 & 2.374 & 1.193 & 0.269 & 0.000 \\
\hline
\end{tabular}

Notes: The 2011-2014 treatment effect is defined in equation (4). See footnote 24 for the definition of the year-specific treatment effects. The permutationbased p-values are generated using the distribution of placebo effects from the donor pool. Rank is equal to the rank of a vessel's treatment effect relative to all placebo effects (Abadie et al., 2010; <mac_ce:cross-ref refid="bib42"'> Munasib and Rickman, 2015). Pre-intervention fit is the root mean squared prediction error for the pre-intervention trends in net revenue.

treatment effect reflects the true effect of the intervention if we obtained similar or larger estimates when the intervention is artificially reassigned to units not directly exposed to the intervention (Abadie et al., 2014). Such permutation tests are based on the fact that under the null hypothesis of no effect, units in the control and treatment group are statistically the same. Permutation tests determine the significance of the estimated treatment effect by rearranging the order of the treatment assignment and estimating the effects of these "placebo" interventions. If the original estimated effect is large relative to the reference distribution of the placebo effects, then we have confidence that the null hypothesis of no effect is false (Bertrand et al., 2004). As in classical statistical inference, we can perform significance tests of the estimated treatment effect through the use of p-values. Specifically, a p-value can be constructed by calculating the fraction of placebo effects in the reference distribution greater than or equal to the effect estimated for the treated unit. In this sense, the permutationbased inferential techniques (and associated p-values) are restricted to the question of whether or not the estimated effect of the actual intervention is large relative to the distribution of placebo effects (Abadie et al., 2014). ${ }^{29}$ Notice that since we are not making inference on a larger population from our sample, the reference distribution under permutation inference is not a sampling distribution, nor do the significance tests make distributional assumptions about the error term or rely on large-sample asymptotics-i.e., they are exact and valid for any sample size (Bertrand et al., 2004). ${ }^{30}$ Thus, the reference distribution does not provide information about statistical precision and is not influenced by nonindependence across individuals. $^{31}$

(footnote continued)

Stata's permute command using 5000 permutations.

${ }^{29}$ Note that permutation inference is not limited to a binary treatment variable. Indeed, we use permutation inference to test the significance of continuous variables, such as those in the system of equation (5), as well as the nonlinear equations for the mechanism effects in equations (6)-(8). See Appendix B.3. for more details.

${ }^{30}$ As a robustness check, we also use classical inference techniques that are based on uncertainty arising from sampling error, thereby viewing our data as a single realization of a data-generating process. In particular, we specify a flexible error structure for the DnD and PSW models that allows for a common AR(1) correlation within vessels, as well as vessel-specific heteroskedasticity (cf., Abbott and Wilen, 2010). Our results are robust to the chosen inferential techniques. Results using the above classical inference technique are available from the authors upon request.

${ }^{31}$ By implication, a confidence interval generated from the permutation-based reference distribution does not provide the same information as a confidence interval generated from the classical-based sampling distribution. Because of this, permutation-based inference methods do not produce confidence intervals for tests of statistical significance. 
Table 3

SEM estimation results for the system of equations in (5).

\begin{tabular}{|c|c|c|c|c|c|}
\hline & \multicolumn{5}{|c|}{ Dependent Variable } \\
\hline & $\begin{array}{l}\text { Revenue } \\
\text { (\$ million) }\end{array}$ & $\begin{array}{l}\text { Quota } \\
(1000 \mathrm{mt})\end{array}$ & $\begin{array}{l}\text { Harvest } \\
(1000 \mathrm{mt})\end{array}$ & $\begin{array}{l}\text { Price } \\
(\$ / 100 \mathrm{mt})\end{array}$ & $\begin{array}{l}\text { Cost } \\
\text { (\$ million) }\end{array}$ \\
\hline Treat $\times$ Year $=2011$ & $\begin{array}{l}2.747 \\
(0.000)\end{array}$ & $\begin{array}{l}-2.677 \\
(0.000)\end{array}$ & $\begin{array}{c}-0.173 \\
(0.892)\end{array}$ & $\begin{array}{l}1.799 \\
(0.009)\end{array}$ & $\begin{array}{l}5.188 \\
(0.000)\end{array}$ \\
\hline Treat $\times$ Year $=2012$ & $\begin{array}{l}2.547 \\
(0.003)\end{array}$ & $\begin{array}{c}-2.698 \\
(0.000)\end{array}$ & $\begin{array}{l}0.539 \\
(0.691)\end{array}$ & $\begin{array}{l}0.519 \\
(0.484)\end{array}$ & $\begin{array}{l}3.988 \\
(0.001)\end{array}$ \\
\hline Treat $\times$ Year $=2013$ & $\begin{array}{l}1.767 \\
(0.053)\end{array}$ & $\begin{array}{l}-3.731 \\
(0.000)\end{array}$ & $\begin{array}{l}1.895 \\
(0.360)\end{array}$ & $\begin{array}{l}-0.243 \\
(0.804)\end{array}$ & $\begin{array}{l}1.099 \\
(0.163)\end{array}$ \\
\hline Treat $\times$ Year $=2014$ & $\begin{array}{l}-1.214 \\
(0.122)\end{array}$ & $\begin{array}{l}-3.197 \\
(0.000)\end{array}$ & $\begin{array}{l}4.964 \\
(0.000)\end{array}$ & $\begin{array}{l}2.054 \\
(0.002)\end{array}$ & $\begin{array}{l}-0.046 \\
(0.976)\end{array}$ \\
\hline Quota (1000 mt) & & & $\begin{array}{l}1.447 \\
(0.000)\end{array}$ & & \\
\hline Harvest (1000 mt) & $\begin{array}{l}0.789 \\
(0.000)\end{array}$ & & & $\begin{array}{c}-0.019 \\
(0.000)\end{array}$ & $\begin{array}{l}0.482 \\
(0.000)\end{array}$ \\
\hline Price $(\$ / 100 \mathrm{mt})$ & $\begin{array}{l}6.270 \\
(0.000)\end{array}$ & & & & \\
\hline Vessel Effects & Yes & Yes & Yes & Yes & Yes \\
\hline Year Effects & Yes & Yes & Yes & Yes & Yes \\
\hline Observations & 119 & 119 & 119 & 119 & 119 \\
\hline$R^{2}$ & 0.524 & 0.753 & 0.273 & 0.268 & 0.194 \\
\hline
\end{tabular}

Notes: p-values in parentheses using permutation inference; $R^{2}$ refers to the proportion of variation explained by the independent variables after removing vessel and year fixed effects.

\section{Results}

\subsection{Total effects of the closure}

The estimated propensity scores (Fig. A-VI) provide evidence that blindly applying the DnD model to our sample without exploring whether the control group is sufficiently similar to the treated group would lead to potentially misleading results. There is one treated vessel that differs significantly from all other vessels in regards to pre-intervention annual trends in net revenue, and thus does not have a good comparison unit within the control group. ${ }^{32}$ Given the lack of suitable comparison units, we remove the off-support vessel from our sample for all estimates presented hereafter, and note that our estimates represent average treatment effects for only six of the seven vessels in the treatment group. ${ }^{33}$

The estimated average treatment effect of the closure on net revenue for the DnD, PSW, and SCM models are presented in Fig. 4, where a unique treatment effect is estimated for each post-intervention year. In general, the estimated average treatment effects for all models provide little evidence of a negative effect on net revenue. Estimated treatment effects for the PSW and SCM models are not meaningfully different from those obtained from the DnD model using the trimmed sample, even though the PSW and SCM approaches give greater care to balancing treatment and control units based on preintervention outcomes. Indeed, the range in the average effect across models is $-\$ 2.15$ million to $-\$ 1.25$ million in 2011 , $-\$ 1.75$ million to $-\$ 1.35$ million in 2012 , $-\$ 0.16$ million to $-\$ 0.14$ million in 2013 , and $+\$ 0.15$ million to $+\$ 0.18$ million in 2014. Using the results of the DnD model, these estimated effects amount to an average annual change in net revenue of $-29.3 \%,-28.8 \%,-3.5 \%$, and $+3.6 \%$ for the years $2011-2014$, respectively. While all three models suggest that there was an economically meaningful negative effect of the closure for the first two years, none of the estimated average treatment effects are significant at the $10 \%$ level for any year. ${ }^{34}$ Thus, the estimated treatment effects are not large relative to those generated by randomly assigning units to the treatment group, thereby decreasing our confidence that the sizeable negative effects reflect any actual effect of the closure.

The SCM results from equation (4) for each treated vessel display a large degree of heterogeneity across vessels

\footnotetext{
32 Propensity score estimation results and the balancing of pre-intervention trends in net revenue are presented in Table A-II and Table A-III. Note that balance is significantly improved with the trimmed sample after dropping the off-support treated vessel (Table A-II). The SCM results for the off-support vessel also confirm this result (Fig. A-VII).

33 Dropping the off-support vessel from our sample has a notable effect on the estimated treatment effects; indeed, DnD estimates for net revenue that include the off-support vessel are considerably larger (more positive) than those obtained using the trimmed sample, suggesting that the closure had a positive (but insignificant) effect on net revenue in most years when this vessel is included (Fig. A-VIII). However, such an interpretation is tenuous due to the lack of a good counterfactual for the off-support vessel.

${ }^{34}$ In fact, only the estimated average effects for the year 2011 for the DnD and PSW models came "close" to being significant at the $10 \%$ level with p-values equal to 0.127 and 0.120 , respectively.
} 


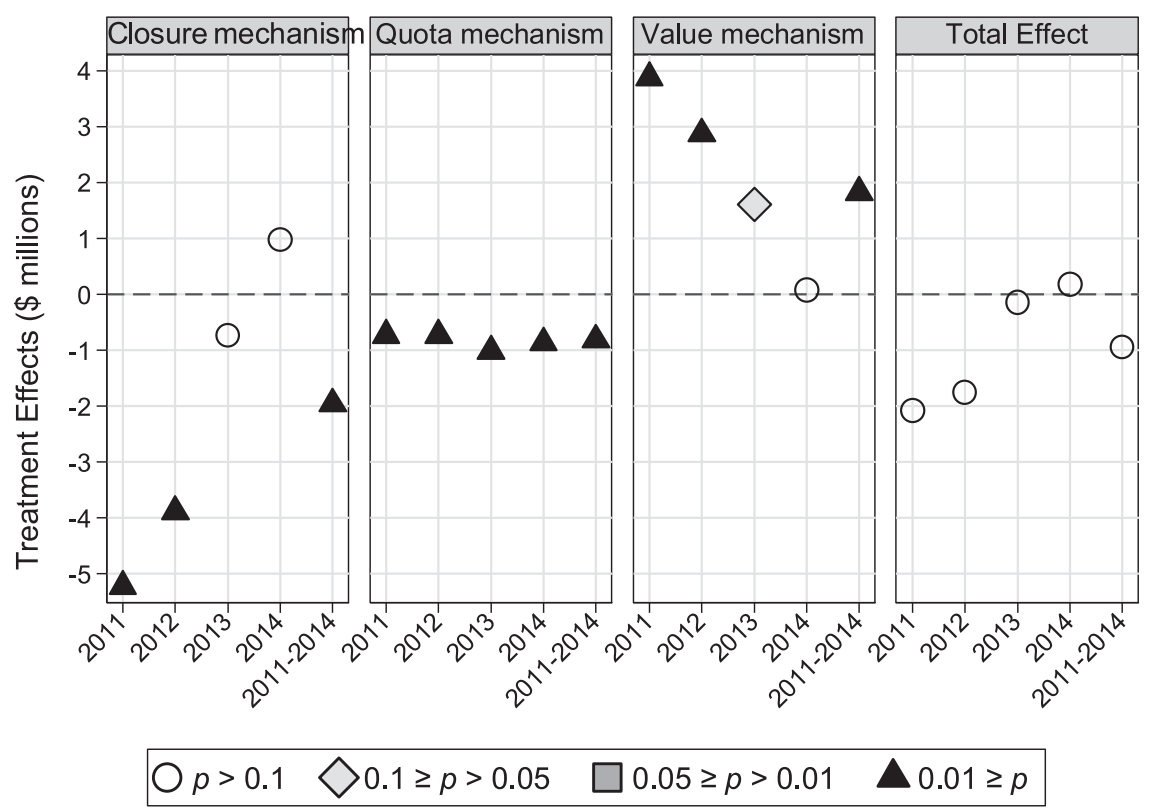

Fig. 5. Point estimates of the direct and indirect displacement, quota, and value mechanism effects from the SEM model, along with the total effect of the closure on net revenue. Note: The color of the markers indicates statistical significance of estimates based on different critical p-values (p). 2011-2014 denotes the average effect across all post-intervention years.

(Table 2). ${ }^{35}$ For example, the insignificant negative average effect on net revenue in 2011 (Fig. 4) is driven by a large and significant effect for a single vessel (Vessel 3), while four of the remaining five vessels were actually better off with the closure, although insignificantly so. In contrast, the negative average effect in 2012 is comprised of smaller, yet significant, effects for three different vessels (Vessels 1, 4, and 6). Only one vessel had a significant average negative effect over all postintervention years (Vessel 4), while only one vessel did not have a single significant negative effect in any given postintervention year (Vessel 2). It is interesting to note that the annual treatment effects for Vessels 2 and 3 move in opposite direction than the rest of the treated vessels, suggesting that there are likely structural differences in the responses and outcomes of vessels to the closure. Overall, the results from the SCM demonstrate that the treatment effects of the closure are heterogeneous across vessels and that the insignificant average treatment effects in Fig. 4 hide the existence of significant treatment effects at the individual vessel level.

\subsection{Intermediary effects of the closure}

While Fig. 4 provides little support for the existence of a treatment effect on net revenue at the aggregate level, the total effects may be disguising important effects on the intermediate variables that comprise net revenue. Indeed, estimates of the SEM parameters in the system of equation (5) (Table 3 and Fig. A-X) reveal the existence of adverse direct effects of closure on the intermediate variables quota and cost. The reduced Atka mackerel TACs in areas 542 and 543 clearly had a significant and prolonged negative direct effect on the total quota allocated to the treated vessels, which became more negative over time in response to declining Atka mackerel allowable biological catches (Fig. A-I) ${ }^{36}$ Further, treated vessels experienced a relatively large and significant direct effect on cost (conditional on harvest) in the first two years after the closure, suggesting that the closure itself increased the average cost of production as vessels were forced to fish their Atka mackerel quota in less productive areas and/or target higher-cost species. ${ }^{37}$

The adverse effects on quota and cost, however, are offset by positive direct effects on the intermediate variables price and revenue. The direct effect on harvest (conditional on quota) is relatively small and insignificant in most years, apart from a large and significant increase in 2014, suggesting that harvest was not adversely affected by the closure itself. Rather,

\footnotetext{
${ }^{35}$ SCM results were obtained using the Stata user-written command synth_runner (Quistorff and Galiani, 2016). For most treated vessels in the trimmed sample, the difference in the trend in net revenue for pre-intervention years is close to zero, as indicated by the root mean square prediction error in Table 2 and by the SCM plots in Fig. A-IX. Also note that the synthetic controls are largely based on four vessels from the donor pool (Table 2).

${ }^{36}$ The average treatment effects for quota imply an average change in quota of $-10.8 \%,-11.0 \%,-15.4 \%$, and $-13.4 \%$ for the years $2011-2014$, respectively, relative to what quota would have been in the absence of the closure.

${ }^{37}$ The average treatment effects for cost imply an average change in cost of $+35.3 \%,+25.7 \%,+7.9 \%$, and $0 \%$ for the years $2011-2014$, respectively, relative to what cost would have been in the absence of the closure.
} 
treated vessels were able to shift their harvest towards species whose annual quotas had not been exhausted in years prior to the closure (e.g., rock sole and Pacific cod) and species that have no quota associated with A80 (e.g., pollock). ${ }^{38}$ Some of these species had higher average wholesale prices and recovery rates relative to Atka mackerel, resulting in positive and significant direct effects on price (conditional on harvest) and revenue (conditional on harvest and price), respectively, in multiple years after the implementation of the closure. ${ }^{39}$

The direct effects in Table 3 suggest that the closure impacted vessels negatively through a reduction in quota and an increase in cost, but that these negative impacts were offset through an increase in price and revenue. However, as depicted in Fig. 2b, these estimates do not account for the existence of several indirect effects of the closure as the direct effects permeate through several different paths before reaching net revenue. As an example, consider the total annual effect of a one-unit reduction in quota, where a unit is defined as $1000 \mathrm{mt}$. The extent to which this affects net revenue depends on how reduced quota affects harvest, and in turn, how harvest affects price, revenue, and cost. From Table 3, we see that a one-unit reduction in quota does not simply reduce harvest by a corresponding unit; rather, harvest declines by approximately 1.44 units on average, which is indicative of reductions in quota that do not match the composition of species comprising vessels' harvest..$^{40}$ In turn, the reduction in harvest has the effect of reducing revenue by $\$ 1.14$ million on average (1.44 units $\times \$ 0.789$ million/unit), all else equal. This negative impact on revenue, however, is offset by the fact that a one-unit reduction in harvest results in a $\$ 0.019$ per unit increase in price, on average. In turn, the increase in price has the effect of increasing revenue by $\$ 0.17$ million (1.44 units $\times \$ 0.019 /$ unit $\times 6.270$ million). Together, the total effect of a one-unit reduction in quota is thus a $\$ 0.97$ million reduction in revenue. When combined with the $\$ 0.694$ million reduction in cost associated with the reduction in harvest (1.44 units $\times \$ 0.482$ million/unit), the total effect of a one-unit reduction in quota on net revenuei.e., the "quota mechanism"-is equal to $-\$ 0.276$ million ( $\$ 0.694$ million - \$0.97 million).

The estimated effects of the quota, displacement, and value mechanisms in equation (6) through (8) and the estimated total effects are displayed in Fig. 5 and account for both the direct and indirect effects of closure on net revenue. ${ }^{41}$ The displacement mechanism clearly had a large and negative impact on net revenue in the first two years following the onset of the closure, indicating that the closed areas in isolation would have cost a vessel $\$ 5.2$ and $\$ 3.9$ million in net revenue on average in 2011 and 2012, respectively, if the vessel had the same amount of quota to harvest but had not been able to increase the value of its harvest by shifting to other species with higher wholesale prices and/or recovery rates. The negative effects of the displacement mechanism are the main driver of the negative total effects of closure in 2011 and 2012 ; however, these effects disappear by 2013, perhaps indicating that vessels were able to adjust their harvesting operations to the new regulations after two costly adjustment years. In contrast, the quota reduction had a negative impact on net revenue over the entire post-intervention period, indicating that a vessel would have lost between $\$ 0.73$ and $\$ 1.01$ million in net revenue on an annual basis had quota simply been reduced, all else equal. The sustained impact of quota on net revenue likely reflects the relative difficulty of adjusting harvesting practices to lower overall quotas, compared to harvesting the same quota in different areas. However, the negative effects associated with both mechanisms can be offset if opportunities exist to increase the wholesale value of harvest. Indeed, Fig. 5 shows that the value mechanism is nearly large enough to offset the negative effects of the closure and quota mechanisms in 2011 and 2012, making the total effect of the closure on average net revenue negligible and not statistically different from zero.

\subsection{Investigating potential spillover effects}

As previously discussed, one potential concern regarding our identification strategy is that the treatment may contaminate the control group through spillover effects as treated vessels shift their fishing effort to areas historically fished by control units. To address this concern, we compare the average pre- and post-intervention levels of "congestion" for control vessels in each month, where congestion is measured as the number of other vessels (both treated and control) that conducted a haul in the same area and day as a control vessel. ${ }^{42}$ As shown in Fig. A-XVI, congestion levels followed the same general annual pattern pre- and post-intervention, with some minor differences in certain months of the year. While many of these monthly changes in average congestion are statistically different from zero, most of them are both relatively small (typically less than one vessel) and negative, thereby suggesting that the congestion levels for control vessels were relatively unaffected by the closure. However, it could be the case that congestion levels remained relatively stable because the shifting effort of treated vessels induced the control vessels to move from their historical fishing areas. However, there are at least two reasons why such an effect is likely negligible. First, a large portion of the fishing effort of the treated vessels

\footnotetext{
38 See Fig. A-XI, Fig. A-XII, and Fig. A-XIII.

39 See Fig. A-XIV and Fig. A-XV. The recovery rate for a species is the proportion of the harvested weight of the fish that is left over after processing. Thus, a higher recovery rate results in increased revenue, conditional on harvest weight and unit wholesale prices. Note that the positive and significant treatment effects on revenue are not driven by changes in income from other sources, such as quota leases and/or tendering.

40 This phenomenon is known as the "catch-quota balancing" problem, and is a well-known problem within multispecies quota systems generally (Copes, 1986; Sanchirico et al., 2006), and for the A80 fisheries particularly (Abbott et al., 2015).

${ }^{41}$ Note that, because net revenue is defined as revenue minus cost and we use the DnD estimator for each equation in (5), the total effect of closure on net revenue from the SEM (i.e., $\delta^{q u o t a}+\delta^{\text {displacement }}+\delta^{\text {value }}$ ) is necessarily equal to the DnD estimator for net revenue (i.e., $\delta^{\text {DnD }}$ from equation ( 1 )).

42 For this analysis, we use the Alaska Department of Fish and Game statistical reporting areas (often referred to as a Stat6 areas), which are spatially more refined than the NMFS management areas. Stat 6 areas are typically $1^{\circ}$ longitude by $1 / 2^{\circ}$ latitude (approximately $60 \mathrm{~km} \times 60 \mathrm{~km}$, but smaller poleward and often in areas near land).
} 
shifted towards management area 541 where the control vessels had very little presence (Table 1 and Fig. A-XVII). Second, the average proportion of monthly fishing effort allocated to the NMFS management areas by the control group underwent only minor post-intervention changes (Fig. A-XVIII). Further, for those months and areas that experienced less fishing effort post-intervention (e.g., months 8-11 in area 509), relatively few of these months correspond to an increase in fishing effort in the same area by the treated vessels. Thus, in general, there is little evidence to suggest that the closure contaminated the control group through congestion externalities.

Another potential source of contamination stems from the transferability of quota across vessels. Prior to the closure, there were virtually no monetary quota transactions, primarily for two reasons: 1 ) seven vessels (four treated and three control) remained in the limited-access sector after A80 was implemented, and quota cannot be exchanged between a cooperative and a limited-access sector; 2) companies primarily fish their own target and PSC allocations. As noted earlier, all vessels in the limited-access sector formed a second cooperative in 2011, thereby creating an avenue through which additional quota exchanges could take place. Indeed, Fig. A-XX shows that quota generally flowed from the treated to the control group after the closure. If the increased flow of quota was in response to the closure, it is possible that the control vessels were better off than they would have been without the closure, thereby biasing our estimator of the treatment effect downwards. There are at least three reasons, however, why the potential contamination is minimal. First, only one vessel in the treated group is part of a company that has vessels in the control group. Thus, within-company transfer opportunities largely remained unchanged with the closure and most exchanges were contained within the treated and control groups. Second, the average amount of quota leased (1.18 thousand $\mathrm{mt}$ ) and royalties paid ( $\$ 0.11$ million) by the control group represented only $6.88 \%$ and $0.96 \%$ of harvests and variable costs, respectively, in the year with the largest exchange of quota (2013). Third, nearly all leased quota after the closure was for yellowfin sole, which allowed the treated group to harvest at most 5.5\% above their annual yellowfin sole allocation (Fig. A-XI), which was worth roughly $\$ 0.49$ million per vessel in wholesale revenue, or $2.7 \%$ of average total revenue. Altogether, this suggests that while the treatment may have caused some positive spillover to the control group through quota exchanges, the amount of quota exchanges after the closure appears to be small, and any contamination is likely minimal and inconsequential for our results.

\subsection{Investigating potential confounding factors}

While the possibility of contamination via congestion is likely small and inconsequential for our results, there may be other challenges for our identification strategy, such as changes in exogenous factors at the time of intervention that disproportionately affected the treated vessels. The price of Pacific ocean perch increased sharply in 2011 (Fig. A-XIV) for reasons unlikely related to the closure. ${ }^{43}$ Given the lack of quota allocated to control vessels for Pacific ocean perch, the increase in price disproportionately benefited treated vessels, thereby violating our assumption that the time varying factor in equation (1) influences the outcome variable equally across all vessels. Indeed, the increased price for Pacific ocean perch likely explains some of the positive price and value effects in 2011, and thus, the overall effect of the closure would likely have been more negative in the absence of this exogenous shock.

The inclusion of annual fixed effects prevents us from separately controlling for the price of Pacific ocean perch in estimating the overall effect of the closure in equation (1). However, we can use the treatment effect decomposition in Section 3.6 to obtain an estimate of the overall effect of the closure without the influence of the increased price if we are willing to assume that the positive treatment effect on price in 2011 is driven entirely by the increased price of Pacific ocean perch. Specifically, we re-estimate the system of equations in (5) while constraining the 2011 treatment effect on price to be zero and obtain new estimates for the quota, displacement, and value mechanisms in equation (6) through (8). In turn, we obtain a new estimate of the overall effect of the closure by summing together the new estimates for the three exhaustive mechanisms.

The resulting estimates of the overall treatment effect and mechanisms are not considerably different from the original estimates, although the overall effect becomes slightly more negative $(-\$ 2.49$ million) and significant $(p$-value $=0.054)$ in 2011 (Fig. A-XIX). Thus, the exogenous price shock does not affect our results in a meaningful way. While it is unlikely the increased price of Pacific ocean perch fully explains the positive treatment effect on price in 2011, this exercise provides a conservative estimate of the influence of the price shock on our estimate of the overall effect. More generally, this exercise demonstrates how mediation analysis can be used to explore the sensitivity of results to potentially confounding factors, provided one is able to isolate the path through which the confounding factor operates.

\section{Conclusion}

Marine reserves are a primary tool utilized to protect the marine environment. While many long-term benefits have been identified, there has been limited attention given to ex post evaluations of the potential short-run costs of these closures on

\footnotetext{
${ }^{43}$ Pacific ocean perch competes in the global market for rockfish, of which it makes up a significant portion (approximately $20 \%$ in 2013 ). The increase in the wholesale price of Pacific ocean perch is likely due to the decrease in supply from other areas, such as Europe, starting in 2011 (Alaska Fisheries Science Center, 2015).
} 
the fishing industry. This is partially due to the challenges in separating the impacts of the closures from the dynamically evolving changes that are ubiquitous to the commercial fishing industry, as well as a general lack of extensive fishing revenue and cost data. We utilize a unique panel dataset of annual net revenue and multiple program evaluation tools to examine the short-run impact of a large spatial marine closure. We decompose the overall treatment effect of the closure through a mediation analysis, demonstrating how the impact of the closure is the result of multiple counteracting mechanisms that are important for understanding the potential impacts of marine reserves in other settings. More generally, the economic impact of marine reserves will depend on the biological, economic, and institutional setting of the fishery. Therefore, identifying these mechanisms is critical for understanding how fishery policy makers can design policies that achieve the desired objective of a marine reserve while enabling the mechanisms that minimize the potential cost to the fishing industry.

Our analysis indicates that there are no statistically significant negative impacts on average net revenue, although there is considerable vessel heterogeneity that indicates that some vessels did relatively poorly in some years. While displacing vessels from productive fishing grounds was particularly costly in the first two years after the closure, vessels were able to offset this cost by shifting their fishing operations to target other valuable species outside of the closure. We note, however, that there are several sources of bias that may push our estimates slightly towards zero, thereby deflating the estimated impact of the closure. For example, positive spillover effects from the exchange of quota between treated and control vessels may have made the control vessels better off after the closure than they would have been otherwise. In addition, a positive and exogenous shock to prices for Pacific ocean perch likely improved treatment vessel outcomes after the closure compared to what they would have been. Further, other regulatory changes that were relaxed with the closure, such as temporal restrictions for targeting Atka mackerel in area 542 (see Hicks and Schnier, 2010), likely provided additional flexibility for the treated vessels to respond to the closure. Thus, while the influence of many of these confounding factors is likely to be small (as we demonstrate in our analysis), they must be considered when interpreting our results.

Several features of the BSAI groundfish fisheries contributed to reducing the cost of the closure. The annual harvest allocations of the six A80 target species are generally not in balance with the rate at which they are encountered by fishing gear. The resulting slack in quota constraints (Fig. A-XI) gave vessels the flexibility to substitute towards species whose quotas had not been exhausted in years prior (e.g., rock sole). If fishing gear had been perfectly selective so that all quotas had been exhausted prior to the closure, the relative economic impact would have likely been much more substantial. ${ }^{44}$ Similarly, not all species encountered by gear are managed by allocated harvest quotas. Instead, vessels are allowed to retain a certain percentage of catch of "non-allocated" species on a trip-by-trip basis, providing another avenue through which vessels could substitute towards harvesting other species outside of the closure (e.g., pollock; Fig. A-XII). Thus, the economic impact of the closure would have likely been more severe had regulations required the catch of all non-allocated species to be discarded. Finally, groundfish fisheries in the BSAI are managed such that the sum of TACs for all managed species cannot exceed an overall ecosystem cap of two million mt. Thus, the reduction in TAC for Atka mackerel created room for TACs of other groundfish species to be increased closer to their biological limits. Without this management feature, the quota mechanism could have been much more severe.

Our work in this paper demonstrates how modern program evaluation methods can accurately capture the trade-offs of alternative valuable uses of marine resources. In particular, our analysis reveals the value of collecting information on net revenue and designing marine reserves in a way that can be evaluated retrospectively, both of which are essential components of evidence-based policy making. Neglecting to collect information on costs and utilizing "revenue at risk" or gross revenue alone provides a misleading view of how industry is able (or not able) to adapt to marine reserves. Similarly, not having an adequate comparison group hinders estimation of the counterfactual of what net revenue would have been without the reserve. In the absence of net revenue information and/or an adequate comparison group, policy evaluations will likely be forced to rely on welfare estimates generated by more structural econometric models of how fishers respond to marine reserves (e.g., Smith and Wilen, 2003; Haynie and Layton, 2010). While such models have advanced considerably in recent years and have the capability of capturing many aspects of the spatiotemporal behavior of fishers, their ability to accurately predict how fishers will respond to a marine reserve depends on how well the model represents fishers' actual decision process and whether structural parameters estimated using data prior to the closure will be valid after the closure (Valcic, 2009; Reimer et al., 2017). Therefore, building a body of empirical evidence regarding the short-run economic impacts of marine reserves, as well as the mechanisms through which they are realized, remains critical for policy makers' ability to design better policies that achieve the intended goals of a marine reserve.

\section{Appendix A. Supplementary data}

Supplementary data related to this article can be found at https://doi.org/10.1016/j.jeem.2018.01.009.

${ }^{44}$ This thought exercise changes the baseline of our analysis from a world in which a catch-quota balancing problem exists to a world in which resources are more perfectly utilized, underscoring the important role of initial conditions in program evaluations. 


\section{References}

Abadie, A., Diamond, A., Hainmueller, J., 2010. Synthetic control methods for comparative case studies: estimating the effect of California's tobacco control program. J. Am. Stat. Assoc. 105 (490), 493-505.

Abadie, A., Diamond, A., Hainmueller, J., 2014. Comparative politics and the synthetic control method. Am. J. Polit. Sci. 59 (2), $495-510$.

Abadie, A., Gardeazabal, J., 2003. The economic costs of conflict: a case study of the Basque country. Am. Econ. Rev., 113-132.

Abbott, J.K., Haynie, A.C., Reimer, M.N., 2015. Hidden flexibility: institutions, incentives and the margins of selectivity in fishing. Land Econ. 91 (1), $169-195$.

Abbott, J.K., Wilen, J.E., 2010. Voluntary cooperation in the Commons? Evaluating the sea state program with reduced form and structural models. Land Econ. 86 (1), 131-154.

Abesamis, R.A., Russ, G.R., 2005. Density-dependent spillover from a marine reserve: long-term evidence. Ecol. Appl. 15 (5), $1798-1812$.

Alaska Fisheries Science Center, 2015. In: Wholesale Market Profiles for Alaska Groundfish and Crab Fisheries, National Marine Fisheries Service NOAA. Angrist, J.D., Pischke, J.S., 2009. Mostly Harmless Econometrics: an Empiricist's Companion. Princeton University Press, Princeton, New Jersey.

Baron, R.M., Kenny, D.A., 1986. The moderator mediator variable distinction in social psychological-research - Conceptual, strategic, and statistical considerations. J. Pers. Soc. Psychol. 51 (6), 1173-1182.

Berman, M., 2006. Modeling spatial choice in ocean fisheries. Mar. Resour. Econ. 21 (4), 375.

Berman, M.D., 2008. Endangered species, threatened fisheries: science to the rescue! Evaluating the congressionally designated Steller sea lion research program. Mar. Pol. 32 (4), 580-591.

Bertrand, M., Duflo, E., Mullainathan, S., 2004. How much should we trust differences-in-differences estimates? Q. J. Econ. 119 (1), $249-275$.

Blundell, R., MaCurdy, T., 1999. In: Ashenfelter, Orley, Card, David (Eds.), Labour Supply: a Review of Alternative Appraoches, vol. 3. , Elsevier, pp. 1560-1618.

Bohn, S., Lofstrom, M., Raphael, S., 2014. Did the 2007 legal Arizona workers Act reduce the State's unauthorized immigrant population? Rev. Econ. Stat. 96 (2), 258-269.

Brito, C., Pearl, J., 2002. A new identification condition for recursive models with correlated errors. Struct. Equ. Model. 9 (4), $459-474$.

Card, D., 1990. The impact of the mariel boatlift on the miami labor market. Ind. Labor Relat. Rev. 43 (2), 1-14.

Card, D., Krueger, A.B., 1994. Minimum wages and employment: a case study of the fast-food industry in New Jersey and Pennsylvania. Am. Econ. Rev. 84 (4), 772-793.

Chen, S.H., Mu, R., Ravallion, M., 2009. Are there lasting impacts of aid to poor areas? J. Publ. Econ. 93 (3-4), 512-528.

Copes, P., 1986. A critical review of the individual quota as a device in fisheries management. Land Econ. 62 (3), $278-291$.

Ferraro, P.J., 2009. Counterfactual thinking and impact evaluation in environmental policy. N. Dir. Eval. 2009 (122), 75-84.

Ferraro, P.J., Hanauer, M.M., 2014. Quantifying causal mechanisms to determine how protected areas affect poverty through changes in ecosystem services and infrastructure. Proc. Natl. Acad. Sci. Unit. States Am. 111 (11), 4332-4337.

Fissel, B., Dalton, M., Felthoven, R.G., Garber-Yonts, B., Haynie, A.C., Himes-Cornell, A., Kasperski, S., Lee, J., Lew, D.K., Seung, C.K., 2015. Stock Assessment and Fishery Evaluation Report for the Groundfish Fisheries of the Gulf of Alaska and Bering Sea/Aleutian Islands Area: Economic Status of the Groundfish Fisheries off Alaska, 2014.

Gaines, S.D., Lester, S.E., Grorud-Colvert, K., Costello, C., Pollnac, R., 2010. Evolving science of marine reserves: new developments and emerging research frontiers. Proc. Natl. Acad. Sci. Unit. States Am. 107 (43), 18251-18255.

Hannesson, R., 1998. Marine reserves: what would they accomplish? Mar. Resour. Econ. 13 (3), 159-170.

Haynie, A.C., Layton, D.F., 2010. An expected profit model for monetizing fishing location choices. J. Environ. Econ. Manag. 59 (2), 165-176.

Heckman, J.J., Ichimura, H., Todd, P.E., 1997. Matching as an econometric evaluation estimator: evidence from evaluating a job training programme. Rev. Econ. Stud. 64 (4), 605-654.

Heckman, J.J., Pinto, R., 2015. Econometric mediation analyses: identifying the sources of treatment effects from experimentally estimated production technologies with unmeasured and mismeasured inputs. Econom. Rev. 34 (1-2), 6-31.

Heckman, J.J., Smith, J.A., 1995. Assessing the case for social experiments. J. Econ. Perspect. 9 (2), 85-110.

Hicks, R.L., Schnier, K.E., 2010. Spatial regulations and endogenous consideration sets in fisheries. Resour. Energy Econ. 32, 117-134.

Hirano, K., Imbens, G.W., Ridder, G., 2003. Efficient estimation of average treatment effects using the estimated propensity score. Econometrica 71 (4), 1161-1189.

Holland, D.S., Brazee, R.J., 1996. Marine reserves for fisheries management. Mar. Resour. Econ. 11, 157-172.

Hooker, S.K., Gerber, L.R., 2004. Marine reserves as a tool for ecosystem-based management: the potential importance of Megafauna. Bioscience 54 (1), 27-39.

Horrace, W.C., Schnier, K.E., 2010. Fixed-effect estimation of highly mobile production technologies. Am. J. Agric. Econ. 92 (5), $1432-1445$.

Imai, K., Keele, L., Tingley, D., Yamamoto, T., 2011. Unpacking the black box of causality: learning about causal mechanisms from experimental and observational studies. Am. Polit. Sci. Rev. 105 (4), 765-789.

Jardine, S.L., Lin, C.Y.C., Sanchirico, J.N., 2014. Measuring benefits from a marketing cooperative in the copper river fishery. Am. J. Agric. Econ., 1-18.

Keele, L., 2015. Causal mediation analysis: warning! Assumptions ahead. Am. J. Eval. 36 (4), 500-513.

King, G., Zeng, L., 2006. The dangers of extreme counterfactuals. Polit. Anal. 14 (2), 131-159.

Kroetz, K., Sanchirico, J.N., Lew, D.K., 2015. Efficiency costs of social objectives in tradable permit programs. J. Assoc. Environ. Resour. Econ. 2 (3), $339-366$.

Morgan, S.L., Winship, C., 2014. Counterfactuals and Causal Inference. Cambridge University Press.

Mu, R., van de Walle, D., 2011. Rural roads and local market development in Vietnam. J. Dev. Stud. 47 (5), 709-734.

Munasib, A., Rickman, D.S., 2015. Regional economic impacts of the shale gas and tight oil boom: a synthetic control analysis. Reg. Sci. Urban Econ. 50 (C), $1-17$.

National Marine Fisheries Service, 2016. U.S. Department of Commerce (Ed.), Fisheries Economics of the United States, 2014NMFS-F/SPO-163. , NOAA Tech. Memo, pp. 237.

National Oceanic and Atmospheric Administration, 1997. Threatened fish and wildlife: change in listing status of Steller sea lions under the endangered species Act. In: Federal Registrar (Ed.), 62 FR 2435

National Oceanic and Atmospheric Administration, 2002. Fisheries of the exclusive economic zone off Alaska; Steller sea lion protection measures for the groundfish fisheries off Alaska; final 2002 harvest specifications and associated management measures for the groundfish fisheries off Alaska. In: Federal Register (Ed.), 67 FR 956.

National Oceanic and Atmospheric Administration, 2010. In: Department of Commerce (Ed.), Revisions to the Steller Sea Lion Protection Measures for the Bering Sea and Aleutian Islands Management Area Groundfish Fisheries.

National Oceanic and Atmospheric Administration, 2014. In: U.S. Department of Commerce (Ed.), Final Environmental Impact Statement Steller Sea Lion Protection Measures for Groundfish Fisheries in the Bering Sea and Aleutian Islands Management Area.

Northern Economics I, 2014. Five-year review of the effects of amendment 80. In: Secondary Northern Economics I (Ed.), Secondary Five-year Review of the Effects of Amendment 80. (Prepared for North Pacific Fishery Management Council. Reprint, Reprint).

Pearl, J., 1995. Causal diagrams for empirical research. Biometrika $82(4), 669-688$.

Pearl, J., 2000. Causality: Models, Reasoning, and Inference. Cambridge University Press, Cambridge.

Pearl, J., 2001. Direct and indirect effects. In: Paper Presented at the Proceedings of the Seventeenth Conference on Uncertainty in Artificial Intelligence. 
Quistorff, B., Galiani, S., 2016. The Synth_Runner Package: Utilities to Automate Synthetic Control Estimation Using Synth Version 1.2.0.

Reimer, M.N., Abbott, J.K., Wilen, J.E., 2017. Fisheries production: management institutions, spatial choice, and the quest for policy invariance. Mar. Resour. Econ. $32(2), 143-168$.

Rosenbaum, P.R., Rubin, D.B., 1983. The central role of the propensity score in observational studies for causal effects. Biometrika 70 (1), 41-55.

Sanchirico, J.N., Holland, D.S., Quigley, K., Fina, M., 2006. Catch-quota balancing in multispecies individual fishing quotas. Mar. Pol. 30 (6), $767-785$.

Sanchirico, J.N., Lew, D.K., Haynie, A.C., Kling, D.M., Layton, D.F., 2013. Conservation values in marine ecosystem-based management. Mar. Pol. 38, 523-530.

Sanchirico, J.N., Wilen, J.E., 2001. A bioeconomic model of marine reserve creation. J. Environ. Econ. Manag. 42 (3), 257-276.

Scheld, A.M., Anderson, C.M., Uchida, H., 2012. The economic effects of catch share management: the Rhode Island fluke sector pilot program. Mar. Resour. Econ. 27 (3), 203-228.

Smith, M.D., Lynham, J., Sanchirico, J.N., Wilson, J.A., 2010. Political economy of marine reserves: understanding the role of opportunity costs. Proc. Natl. Acad. Sci. U. S. A. 107 (43), 18300-18305.

Smith, M.D., Wilen, J.E., 2003. Economic impacts of marine reserves: the importance of spatial behavior. J. Environ. Econ. Manag. 46 (2), $183-206$.

Smith, M.D., Zhang, J., Coleman, F.C., 2006. Effectiveness of marine reserves for large-scale fisheries management. Can. J. Fish. Aquat. Sci. 63 (1), $153-164$. Sobel, M.E., 1987. Direct and indirect effects in linear structural equation models. Socio. Meth. Res. 16 (1), 155-176.

Valcic, B., 2009. Spatial policy and the behavior of fishermen. Mar. Pol. 33 (2), 215-222.

Wabnitz, C.C., Andrefouet, S., Muller-Karger, F.E., 2010. Measuring progress toward global marine conservation targets. Front. Ecol. Environ. 8 (3), $124-129$. 